\title{
Cross-Time Scale Interactions and Rainfall Extreme Events in Southeastern South America for the Austral Summer. Part I: Potential Predictors
}

\author{
Á. G. MuÑOZ \\ International Research Institute for Climate and Society, The Earth Institute, Columbia University, Palisades, New York, \\ and Centro de Modelado Científico, Universidad del Zulia, Maracaibo, Venezuela \\ L. GODDARD AND A. W. ROBERTSON \\ International Research Institute for Climate and Society, The Earth Institute, Columbia University, Palisades, New York \\ Y. KUSHNIR \\ Lamont-Doherty Earth Observatory, Columbia University, Palisades, New York \\ W. BAETHGEN \\ International Research Institute for Climate and Society, The Earth Institute, Columbia University, Palisades, New York
}

(Manuscript received 12 October 2014, in final form 6 July 2015)

\begin{abstract}
The physical mechanisms and predictability associated with extreme daily rainfall in southeastern South America (SESA) are investigated for the December-February season in a two-part study. Through a $k$-mean analysis, this first paper identifies a robust set of daily circulation regimes that are used to link the frequency of rainfall extreme events with large-scale potential predictors at subseasonal-to-seasonal scales. This represents a basic set of daily circulation regimes related to the continental and oceanic phases of the South Atlantic convergence zone (SACZ) and wave train patterns superimposed on the Southern Hemisphere polar jet. Some of these recurrent synoptic circulation types are conducive to extreme rainfall events in the region through synoptic control of different mesoscale physical features and, at the same time, are influenced by climate phenomena that could be used as sources of potential predictability. Extremely high rainfall (as measured by the 95th and 99th percentiles) is associated with two of these weather types (WTs), which are characterized by moisture advection intrusions from lower latitudes and the Pacific Ocean; another three WTs, characterized by above-normal moisture advection toward lower latitudes or the Andes, are associated with dry days (days with no rain). The analysis permits the identification of several subseasonal-to-seasonal scale potential predictors that modulate the occurrence of circulation regimes conducive to extreme rainfall events in SESA. It is conjectured that a cross-time scale interaction between the different climate drivers improves the predictive skill of extreme precipitation in the region.
\end{abstract}

\section{Introduction and rationale}

Extreme rainfall events are of key socioeconomic importance for southeastern South America (SESA), located to the east of the Andes roughly between $25^{\circ}$

๖ Denotes Open Access content.

Corresponding author address: Á. G. Muñoz, International Research Institute for Climate and Society (IRI), Monell Building, Columbia University, 61 Route 9W, Palisades, NY 10964-1000.

E-mail: agmunoz@iri.columbia.edu and $36^{\circ} \mathrm{S}$, as shown by the box in Fig. 1. Floods and droughts impact the infrastructure and a variety of activities in this densely populated region: agriculture, livestock, and hydroelectric power production are exceedingly vulnerable to (although sometimes reliant upon) extreme precipitation events (Mechoso et al. 2001; Carvalho et al. 2002; Bettolli et al. 2010).

Current thinking suggests that austral-summer extreme rainfall events in SESA are produced by mesoscale convective complexes (MCCs; Velasco and Fritsch 1987; Ferreira et al. 2003), extratropical cyclones (e.g., strong baroclinic fronts; Seluchi et al. 2006), and heat 


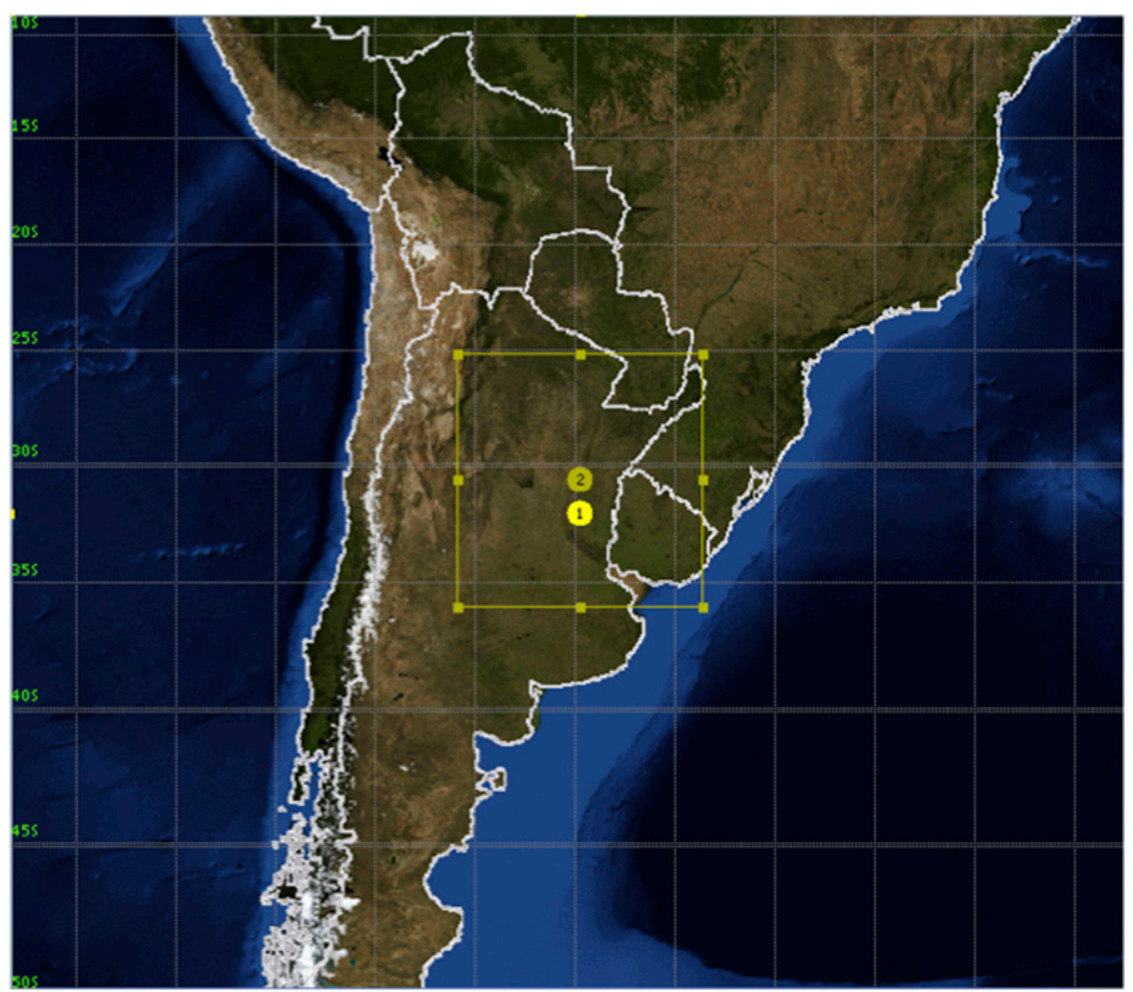

FIG. 1. Location of southeastern South America (SESA) region.

and moisture transport, especially by the South American low-level jet (SALLJ; Salio et al. 2002, 2007; Marengo et al. 2004), as well as by atmospheric rivers, which have been reported to play an important role to the west of SESA in terms of moisture availability in relation to extreme rainfall events (Viale and Nuñez 2011). In this region, MCCs are frequently large in size and intensity, and account for $60 \%$ of the yearly precipitation (Velasco and Fritsch 1987; Mo and Nogues-Paegle 2001; Silva Dias et al. 2002; Salio et al. 2007). These features tend to be closely related, and since particular synoptic systems cause extreme rainfall in SESA (Minetti et al. 1993; Alessandro 1996, 2001; Labraga et al. 2002; Bettolli et al. 2009), it is reasonable to hypothesize that the mechanisms involved are represented in the daily atmospheric circulation regimes. Therefore an analysis of these recurrent circulation types and their seasonal and subseasonal frequency of occurrence provides useful information both about the occurrence of extreme rainfall and about which large-scale climate drivers are most conducive to those extreme events. This relationship between the frequency of occurrence of synoptic circulation patterns, extreme events, and potential large-scale climate predictors is at the core of the framework discussed in this paper.

Previous work examined the relationship between synoptic circulation and daily rainfall statistics (Bettolli et al. 2009), soybean yield variability (Bettolli et al. 2010), and extreme temperatures (Penalba et al. 2013). These studies found circulation regimes that discriminate between the occurrence and nonoccurrence of rainfall and extreme temperature events, and the interannual variability of soybean (yields) in SESA. They suggested that the identified circulation structures could be used as a primary element for monitoring, as well as short- to midrange forecasting in the region. Nonetheless, to the best of our knowledge, the present work is the first study that links extreme rainfall events in SESA to large-scale climate drivers using recurrent synoptic circulation regimes, and that then builds a predictive model that integrates both subseasonal and seasonal potential predictors.

Multiple time scales seem to be involved in the occurrence of extreme rainfall in SESA. At subseasonal time scales, tropical and extratropical phenomena like the Madden-Julian oscillation (MJO) and South Atlantic convergence zone [SACZ, a part of the South American monsoon system (SAMS)] have been found to strongly modulate extreme rainfall via circulation anomalies and MCC activity (Jones and Carvalho 2002; Carvalho et al. 2002, 2004; Petersen et al. 2003; CazesBoezio et al. 2003; Carvalho et al. 2011; Muza et al. 2009). These and other climatic features are also modulated during the seasonal scale by interannual 
perturbations of the Walker and Hadley circulations and the triggering of Rossby waves that takes place during the warm phase of El Niño-Southern Oscillation (ENSO) episodes (Velasco and Fritsch 1987; Carvalho et al. 2004; Grimm and Tedeschi 2009; Muza et al. 2009, and references therein). However, the precise relationship between ENSO episodes and extreme rainfall events has not been extensively studied for South America (Grimm and Tedeschi 2009). Although these features are affected by ENSO teleconnections, they are also present during ENSOneutral years; a predictability study should therefore consider other potential predictors, like the southern annular mode (SAM; Marshall 2003), the South Atlantic dipole (SAD; Nnamchi et al. 2011), and the Atlantic meridional mode (AMM; Foltz and McPhaden 2010), and possible interactions with subseasonal drivers.

The skill of seasonal forecasts has improved remarkably during the last decades (Goddard et al. 2003; Stockdale et al. 2011; Barnston et al. 2012; Barnston and Tippett 2014); however, the subseasonal-to-seasonal prediction of regimes that lead to extreme events is still under development (WMO 2013). It is important to better understand the physical mechanisms underlying extreme precipitation events, how their frequency of occurrence and intensity are modulated by synoptic control, ${ }^{1}$ and what are the potential sources of predictability at seasonal and subseasonal scales. The predictive skill of models considering both seasonal and subseasonal predictors must be explored for SESA and other regions of the world. Moreover, since the circulation regimes are a "filtered version" of the whole circulation field, it is possible that they show a higher predictive skill if used as predictors of extreme rainfall events, by capturing more efficiently the effects of the large-scale climate drivers.

This two-part study uses a weather type (WT) approach (e.g., Robertson and Ghil 1999) to explore the role of daily synoptic circulation regimes and related large-scale climate drivers in the prediction of the frequency of occurrence of extreme rainfall events over SESA during the December-February season. To set the stage for the predictability study that is developed in a subsequent paper, the present study identifies a robust set of circulation patterns that typify the available synoptic states or, figuratively speaking, identifies the letters of an alphabet that could be used to articulate all

\footnotetext{
${ }^{1}$ This makes reference to the fact that mesoscale atmospheric features related to extremes are often controlled by synoptic scale systems; for details, see, for example, Roebber et al. (2008) and Peters and Roebber (2014).
}

the different synoptic events that may occur in SESA, extremes or not. The WTs, or "letters," are then related to extreme rainfall events, and to the associated largescale climate drivers, permitting the identification of potential predictors and their possible (two way) interactions at subseasonal-to-seasonal time scales. The quantitative predictive models and their predictive skill for extreme rainfall in SESA are discussed in a companion paper.

The paper is organized as follows. Section 2 summarizes the datasets and methodology. An analysis of the WTs and extreme event characteristics, as well as the link between WTs and extreme event, is discussed in section 3. Section 4 investigates the link between WTs and climate drivers, at both subseasonal and seasonal scales, and identifies potential predictors. Section 5 is devoted to the discussion of the results, introducing a cross-time scale predictive approach for SESA. Concluding remarks are presented in section 6 .

\section{Data and methodology}

\section{a. Datasets}

The datasets considered in this study involve variables for daily rainfall, daily atmospheric circulation, monthly sea surface temperature anomalies (SSTA), and indices for the SAM, AMM, SAD, MJO, and SACZ. The time period for all the datasets is from December to February (DJF) 1979-2010.

The rainfall fields were computed using the NOAA/ NECEP/CPC unified precipitation gridded dataset (Chen et al. 2008). This product has daily temporal resolution and a spatial resolution of $1^{\circ}$. An analysis of daily circulation variability over SESA (see the small square in Fig. 1) was used, derived from the NCEPNCAR reanalysis project (version 2) $850-\mathrm{hPa}$ geopotential data on a $2.5^{\circ}$ grid (Kalnay et al. 1996; Kistler et al. 1999), for the DJF season. The Extended Reconstructed SST dataset (version $3 \mathrm{~b}, 2^{\circ}$ grid; Smith et al. 2008) was used for sea surface temperature. The Niño-3.4 index is defined by the 3-month running average for the SST anomalies averaged over the area $5^{\circ} \mathrm{S}-5^{\circ} \mathrm{N}, 120^{\circ}-170^{\circ} \mathrm{W}$.

Finally, index datasets for the SAM (Marshall 2003), AMM (Foltz and McPhaden 2010), SAD (Nnamchi et al. 2011), MJO (Wheeler and Hendon 2004), and SACZ (Carvalho et al. 2011) correspond to those in the respective reference. These indices use principal component analysis of certain variables (or sets of variables) in order to describe the variability of the corresponding climate mode. 


\section{b. Methodology}

As mentioned in the previous section, this paper explores the role of particular daily circulation regimes in the occurrence of extreme rainfall events in SESA, through the identification of large-scale drivers at subseasonal-toseasonal scales that are associated with WTs conducive to such extreme events. This subsection deals with the methodological aspects related to the definition of extremes, the determination of a set of WTs that represent physically available states of the system, and how to link a subset of these regimes to both the occurrence of extreme precipitation events and their potential predictors.

The general methodology could be summarized as follows:

1) characterize the frequency of occurrence of extreme events;

2) find and analyze a robust set of circulation regimes that represent the available synoptic states of the system (WTs);

3) identify the link between WTs and extreme events; and

4) identify the link between WTs and climate drivers at different time scales.

This process permits one to define a set of potential predictors based on physical interactions ranging from large-scale drivers to synoptic features to mesoscale mechanism related to extremes, which then could be used to design a statistical forecast model.

In this analysis, the frequency of extreme events was considered instead of total precipitation amounts due to the relative higher potential predictability of this parameter (Moron et al. 2007). On a grid box basis, the number of dry days (precipitation $<1 \mathrm{~mm}$ ) and the number of extremely wet days, exceeding the 95th (dR95p) and 99th (dR99p) percentiles, were computed for all days in each season. The total number of events per grid box $(f)$ was counted, summed over the SESA box (Fig. 1), and normalized by the number of cells $(N=$ $506)$ to define the mean (1979-2010) seasonal frequency of extreme events for each year, $F_{j}$ :

$$
F_{j}=\frac{1}{N} \sum_{i} f_{i j},
$$

where $i$ and $j$ denote the number of grid boxes and years, respectively (Fig. 2).

The circulation regimes were determined using a $k$ means analysis (e.g., Robertson and Ghil 1999). This is a partitioning method that classifies all days into a predefined number of clusters, minimizing the sum of squared Euclidian distances within the set of clusters. Besides projecting the daily geopotential data onto its three leading empirical orthogonal functions, which account for $95 \%$ of the variance, no additional time filtering was applied to the data, thus retaining the annual seasonal cycle, interannual, subseasonal, and synoptic weather time scales that may be connected to the extreme rainfall over SESA.

The $k$-means six-cluster solution was found to yield a near-maximum classifiability index $(\mathrm{CI} \sim 0.9)$ (Michelangeli et al. 1995) and very similar values with respect to solutions with $k>4$, within the range of $k=$ 2-10; therefore it was selected for further analysis. The CI measures the similarity of partitions of the data, obtained from 1000 different initial random seeds of the algorithm; the single partition that matches most closely the remaining ones is then selected. This set of clusters can be interpreted as a set of geopotential regimes that typify the daily variability. Other solutions were explored, verifying that the general features of the circulation regimes presented below are robust and sufficient for the purposes of this study. The WTs analyzed here are qualitatively similar to the ones discussed by Bettolli et al. (2010), which suggests additional robustness in the results.

In principle, not every WT is associated with extreme rainfall events. To identify which WTs are more frequently associated with extreme events a nonparametric statistical test was used, involving resampling the time series 2500 times, each time with an additional lag of one day in order to maintain the transition probabilities.

Precipitation, vertically integrated moisture flux, and SST anomaly composites were computed for the selected $k$-mean solution. All anomalies are computed with respect to the long-term DJF average.

Vertically integrated moisture fluxes were obtained by integrating over the depth of the atmosphere,

$$
\mathbf{Q}=g^{-1} \int_{\mathrm{sfc}}^{\mathrm{top}} \mathbf{V} q d p
$$

where $g$ is the gravitational acceleration, $\mathbf{V}$ is the horizontal velocity vector, $q$ is the specific humidity, and $p$ the atmospheric pressure.

The low-level (up to $850 \mathrm{hPa}$ ) moisture flux divergence was computed as usual:

$$
-\boldsymbol{\nabla} \cdot \mathbf{Q}=-g^{-1} \boldsymbol{\nabla} \cdot \int_{\mathrm{sfc}}^{850 \mathrm{hPa}} \mathbf{V} q d p .
$$

Tests for statistically significant transitions between WTs and for subseasonal frequency of occurrence of WTs 

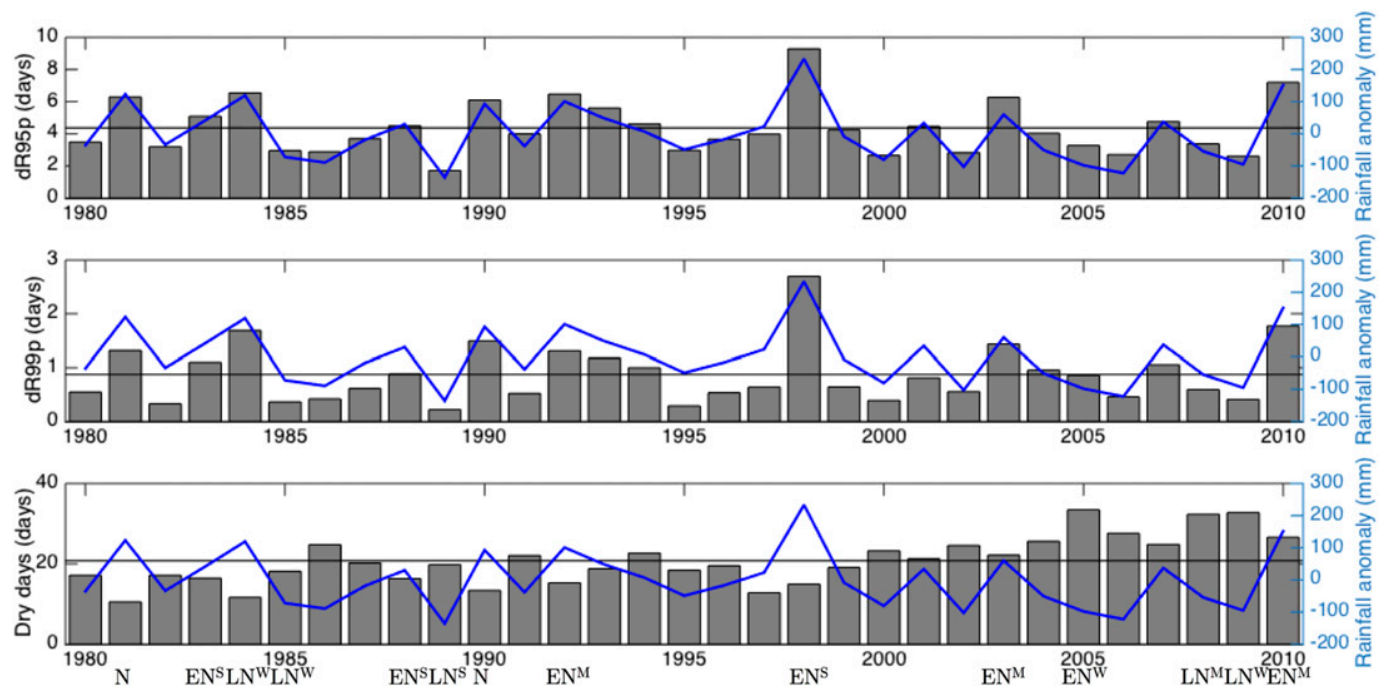

FIG. 2. Mean seasonal frequency of extreme rainfall events per grid box for the peak rainy season (DJF) in SESA, defined in terms of the (top) 95th (R95p) and (middle) 99th percentiles (R99p), and (bottom) no rain (dry days). The solid blue lines represent the total regional mean anomaly $(\mathrm{mm})$. Black lines show the long-term mean for each extreme index. December corresponds to the previous year indicated in the axis. Several strong (S), moderate (M), and weak (W) El Niño (EN) and La Niña (LN) years are indicated at the bottom of the figure (strength indicated by the superscripts). Two particular neutral (N) ENSO years showing high frequency of extreme events are also indicated.

were performed comparing with respect to a random distribution of the events (Vautard 1990). Statistical significance tests for compositing SST for each cluster were performed using a hypergeometric cumulative distribution function; the hypergeometric model is used for each grid box to compute the cumulative probability that at least $m$ successes (positive or negative anomalies) are obtained in $n$ trials (years in which the seasonal frequency of each WT exceeded the 80th percentile of the frequency distribution) from a finite population of size $N$ (the 31 seasons considered in the study). The tests for Spearman correlations between WTs and climate drivers involved the use of a bootstrap resampling method in which the time series were randomized 1000 times.

Finally, tables of contingency between the MJO and SACZ and each WT were computed following Cassou (2008): for each MJO and SACZ phase the anomalous percentage of occurrence of a given regime was plotted as a function of the lead time in days (with WT lagging MJO and SACZ phases). In these plots, values of $0 \%$ indicate no discrimination of the particular phase for the WT whose occurrence is climatological, a $100 \%$ value means that the WT occurs twice as frequently as its climatological value, and $-100 \%$ means no occurrence at all of this WT.

\section{Weather types and extreme rainfall}

This section presents a characterization of the extreme events and WTs, and discusses the link between them.

\section{a. Extreme rainfall}

Although no long-term linear trend is found in the frequency of wet extreme events (Fig. 2), the dry extremes present a statistically significant linear trend $(p<$ 0.01 for an $F$ test of a linear model compared to a constant model); these results require further analysis and will be treated elsewhere. ENSO appears to play an important role in modulating rainfall; strong (e.g., 1997/98) and moderate (e.g., 1991/92, 2002/03, and 2009/10) El Niño events show a higher frequency of days with extremely high rainfall, while strong (e.g., 1988/89) and even weak (e.g., 1984/85) La Niña events exhibit a lower frequency of occurrence of extremely high rainfall. In spite of this, ENSO does not seem to be the only factor explaining the interannual variability of frequency of extreme precipitation events in the region. For example, some ENSO-neutral years (e.g., 1980/81 and 1989/90) show similar frequency of extremely high rainfall events as moderate El Niño years; in particular, the number of extremes during the weak La Niña event of 1983/84 compares to the strong El Niño event of 1982/83. Moreover, the frequency of dry days is not in general related to ENSO, except in particular cases like 1997/98 or 1984/85. Other climate drivers need to be explored in order to explain all these cases.

Statistically significant $(p<0.01)$ correlations exist between the mean precipitation anomaly and the frequency of both wet and dry extremes (not shown). 
(a) WT 1 (327 days)

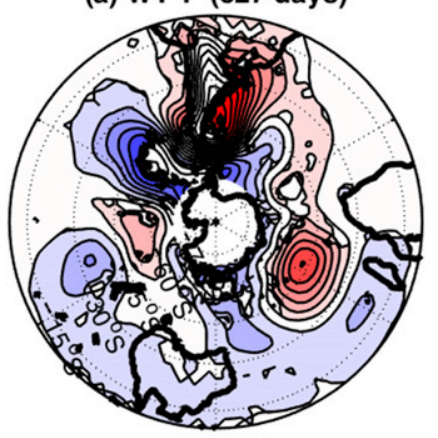

(d) WT 4 (319 days)

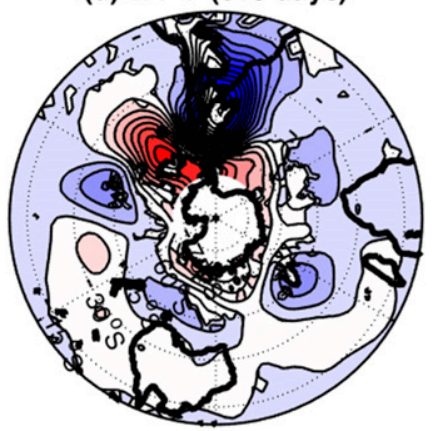

(b) WT 2 (354 days)

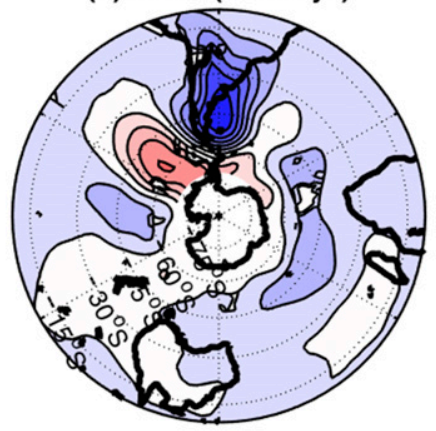

(e) WT 5 (639 days)

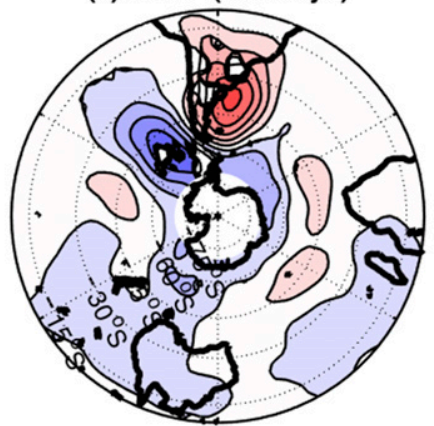

(c) WT 3 (552 days)

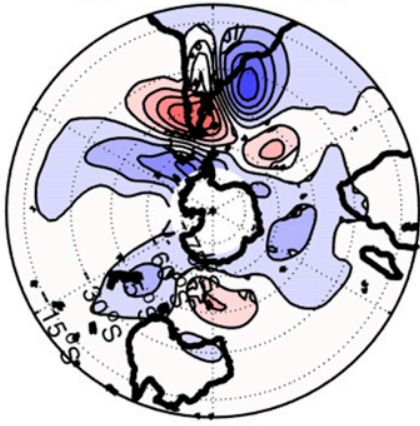

(f) WT 6 (607 days)

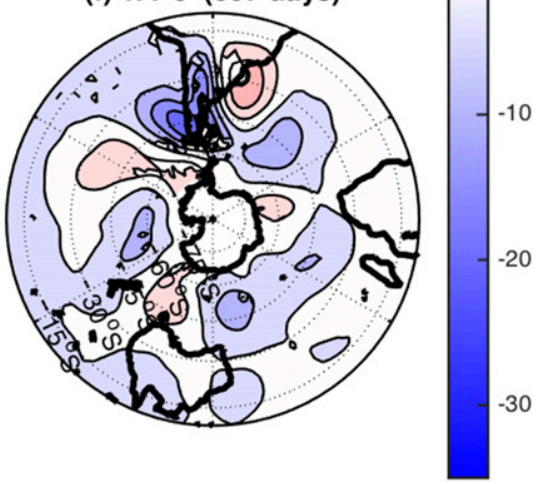

FIG. 3. The $k$-means solution for $k=6$, showing geopotential height anomalies at $850 \mathrm{hPa}$, plotted over the Southern Hemisphere to highlight larger-scale aspects. Contour lines sketch the geopotential height anomalies (gpm), and shaded regions indicate statistically significant $(p<0.05)$ anomalies. Panel titles give the number of days in DJF assigned to each cluster.

Linear and nonlinear regression models indicate that the mean rainfall anomaly could be explored as a predictor for dR95p. The results are not that encouraging for dR99p and dry days [for similar results, see Moron et al. (2006, 2007) and Robertson et al. (2009)].

\section{b. Weather types: Characteristics and link to extremes}

Visual inspection of the geopotential height anomaly clusters (Fig. 3) suggests that circulation regimes (WTs) 3 and 6 are related to the continental and oceanic phases of the SACZ (Carvalho et al. 2002, 2004), respectively. Other WTs show synoptic-scale extratropical wave trains superimposed on the Southern Hemisphere polar jet, and possibly involve stationary Rossby waves meridionally propagating from tropical heat sources, as discussed by Cazes-Boezio et al. (2003). Overall the WTs are similar to the first three EOFs of the 850-hPa geopotential anomaly field, and WTs 1-3 and WTs 4-6 seem quasi-inverse phases of each other, respectively (see Fig. 3). The fact that the WT pairs are not exactly mirror images of each other, ${ }^{2}$ however,

\footnotetext{
${ }^{2}$ Pattern correlations between WTs 1 and 4, WTs 2 and 5, and WTs 3 and 6 are $-0.90,-0.81$, and -0.83 , respectively.
}

may indicate the importance of nonlinear processes. Rainfall anomaly composites (Fig. 4) connect WTs 4-6 to positive precipitation anomalies over SESA, showing very specific spatial distributions: WT 4 yields higher anomalies on the eastern half of SESA, WT 5 locates them on the northwestern quadrant, and WT 6 shows high rainfall basically over the whole SESA.

The total frequency of occupancy, which refers to the number of days that a particular synoptic configuration took place in a given period, ranges from 319 days for cluster 4 ( $\sim 10$ days per season on average) to 639 days for cluster 5 ( $\sim 21$ days per season). In terms of their time evolution, an important advantage of the methodology being used is that it is possible to compute seasonal and intraseasonal statistics related to the circulation patterns, including their transition probabilities (Fig. 5).

A way to analyze the temporal evolution of WTs is through Klee diagrams ${ }^{3}$ (Fig. 5a). These diagrams have been used in other fields (Sirovich et al. 2009) to visualize large genomic datasets, but are used here as a simple way to visualize the daily evolution of the WTs at

\footnotetext{
${ }^{3}$ In honor of Paul Klee (1879-1940).
} 
(a) WT 1 (327 days)

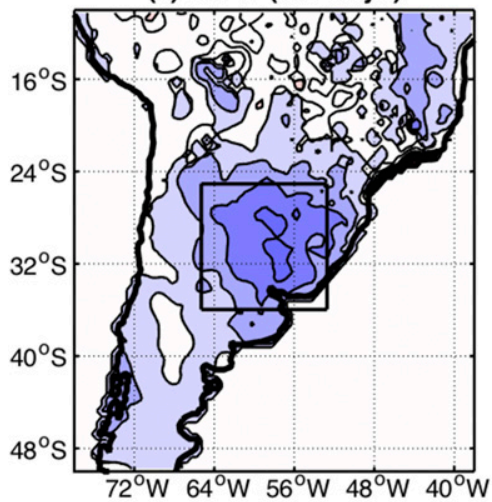

(d) WT 4 (319 days)

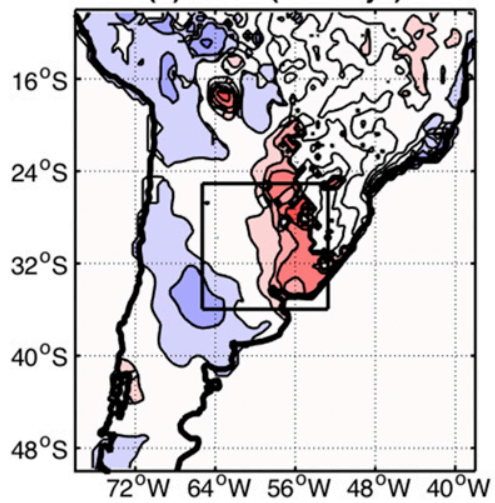

(b) WT 2 (354 days)

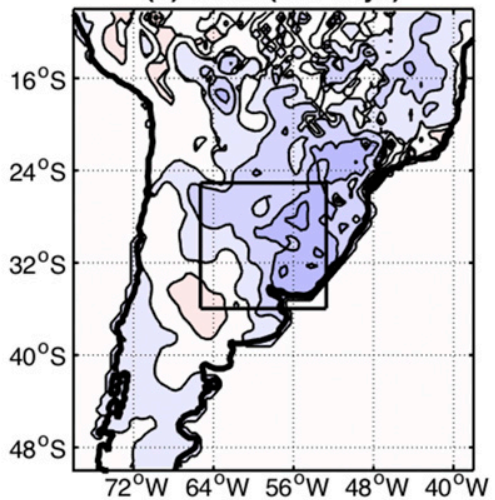

(e) WT 5 (639 days)

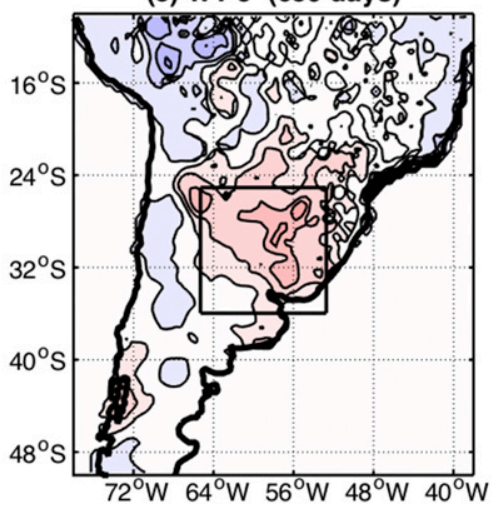

(c) WT 3 (552 days)

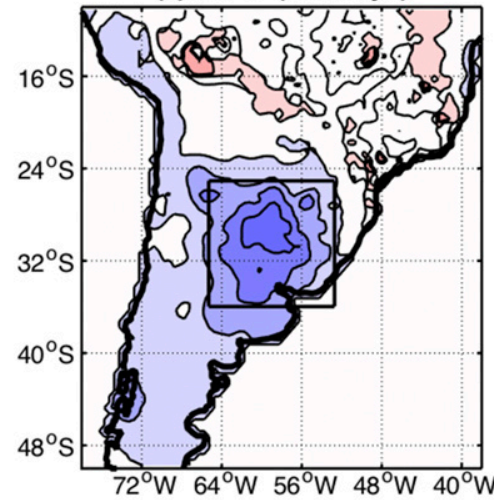

(f) WT 6 (607 days)

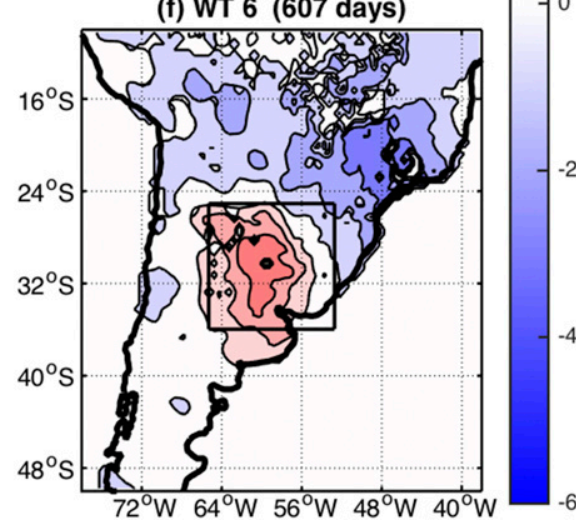

FIG. 4. Rainfall anomaly composites for the six-cluster $k$-means solution. Contour lines sketch the rainfall anomalies (mm), and shaded regions indicate statistically significant $(p<0.05)$ anomalies. The black box shows the location of SESA. Panel titles give the number of days in DJF assigned to each cluster.

both subseasonal and interannual scales. The Klee diagram is also the starting point to compute plots of frequency of occurrence of WTs at subseasonal and interannual scales, and also the transition matrices. They could also be thought as a collection of letters from which a successful decryption algorithm could find sequences of WTs conducive to extreme events. Although this approach is out of the scope of the present work, it will be briefly addressed later in this paper.

Analysis of the daily sequence of WTs within a season from year to year (Fig. 5a, Table 1) indicates that transitions typically occur on a daily basis, although it is more common for WTs 3, 5, and 6 to last for 2-3 days than the other regimes. WTs 2 and 6 are the only types that do not persist beyond 6 days, and none persists more than 10 days. The Klee diagram shows that some atmospheric regimes tend to be more frequent in a particular set of years. For example, WT 4 and its spells tend to be more frequent between the end of the 1980s and the beginning of the 2000s.

The most subseasonally varying regimes are WTs 1 and 4 (Fig. 5b). WT 1 tends to be more frequent at the end of the DJF season than at the beginning, while the opposite is true for WT 4; these are considered here transition configurations between seasons, which could be related to quasi-stationary synoptic features linked to the seasonal migration of the location of maximum solar radiation. WTs 5 and 6 dominate the occupation frequency along the season; WT 5 starts the season with a local minimum on the middle of December, and then peaks around the beginning of January and again at the end of February, decreasing around the middle of January, which is when WT 6 is prevalent. WTs 2 and 3 are fairly constant along the season (their standard deviations are both 0.8 , the minimum value of the set; see Fig. $5 \mathrm{~b}$ ).

In terms of the interannual evolution of the frequency of occupation of the regimes, WTs 6,5 , and 3 are the most prevalent for the period under study (Fig. 5c). There seems to be some relationship between ENSO and the frequency of occurrence of certain WTs. For example, regime 4 tends to have a very low seasonal frequency in certain weak La Niña events, as seen in 1984/85, 2005/06, and 2008/09. Further analysis confirms this relationship later in this paper.

The daily-transition probability matrix, which represents the probabilities that a certain WT persists or 

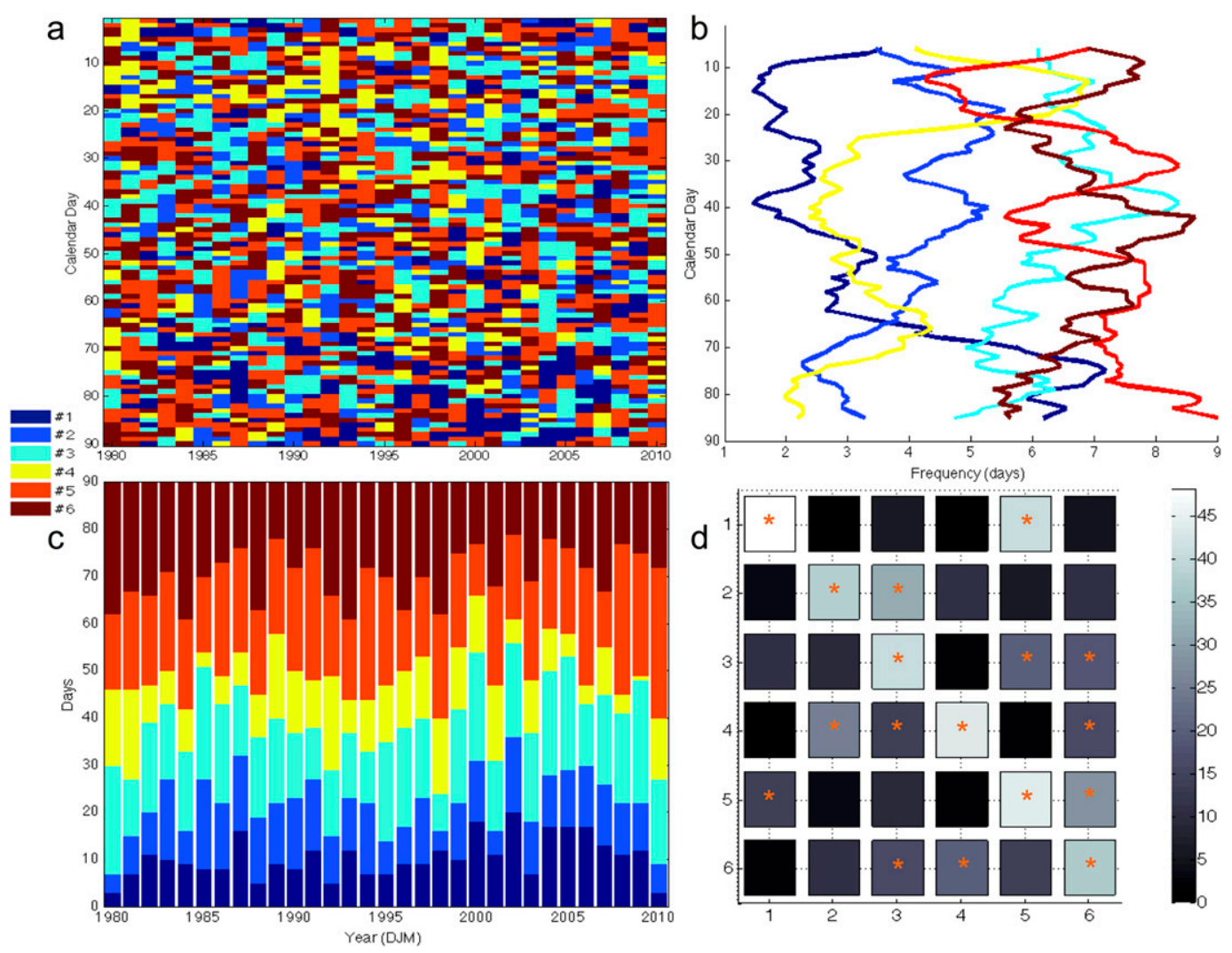

FIG. 5. (a) Klee diagram sketching the daily distribution of WT (see color bar at left) for DJF 1979-2010; calendar days correspond to 1 Dec-28 Feb. (b) Mean occupation frequency within season (days) for each WT, smoothed with an 11-day moving average; the standard deviation for WTs $1-6$ is 1.7, $0.8,0.8,1.4,1.1$, and 0.8 days, respectively. (c) Occupation frequency by season (days). (d) Matrix of daily transition probabilities (\%) between the initial (vertical axis) and final WT (horizontal axis); darker tones correspond to lower probabilities (see color bar), and asterisks indicate statistically significant $(p<0.1)$ transitions.

makes a transition to another WT, (Fig. 5d) indicates persistence probabilities ranging from $48 \%$ (WT 1) to $37 \%$ (WT 6). The strongest non-self-transitions suggest the circuit $5 \rightarrow 6 \rightarrow 4$ (all related to positive rainfall anomaly regimes) $\rightarrow 2 \rightarrow 3 \rightarrow 5$. As explained before, transitions WT $4 \rightarrow$ WT 2 tend to happen faster ( $\sim 1$ day) than the others (1-3 days), and the fastest circuit will typically take around 6-7 days, in agreement with the characteristic times of synoptic-scale propagating disturbances.

Finally, an analysis of the relation between the circulation regimes and extreme seasonal rainfall anomalies was performed for the relative frequency of occurrence of days with rainfall exceeding dR95p and dR99p and dry days by WT (Fig. 6). Extremely wet days are preferentially associated with WTs 4 and 6 , while WTs $1-3$ tend to be more frequent on dry days. WT 5 , on the other hand, has a more complex role; although it is not directly related to the occurrence of any of the "extreme" rainfall events considered in this study, transitions of WT 5 into WT 6 (Fig. 5d) are significantly more probable $(\sim 30 \%)$ than into any other WT $(<14 \%)$, except into itself $(44 \%)$. Since
WT 5 is frequently a precursor of WT 6 , which is statistically related to extremely wet events, and on average it tends to be associated to positive rainfall anomalies (Fig. 4), it is kept along with the other circulation regimes for further analysis.

\section{c. Examples of synoptic control}

As stated before, extreme rainfall events in SESA are regionally associated with the occurrence of three features: baroclinic fronts, heat and moisture advection

TABLE 1. Mean duration and frequency of spells lasting at least 3 and 5 days.

\begin{tabular}{lcccccc}
\hline \hline & WT & WT & WT & WT & WT & WT \\
& 1 & 2 & 3 & 4 & 5 & 6 \\
\hline $\begin{array}{l}\text { Weighted mean } \\
\quad \text { duration }\end{array}$ & 1.4 & 1.3 & 1.5 & 1.4 & 1.7 & 1.6 \\
$\begin{array}{c}\text { Frequency spells } \geq 3 \\
\quad \text { days }\end{array}$ & 27 & 25 & 41 & 32 & 61 & 48 \\
$\begin{array}{c}\text { Frequency spells } \geq 5 \\
\text { days }\end{array}$ & 6 & 4 & 5 & 4 & 13 & 3 \\
\hline
\end{tabular}



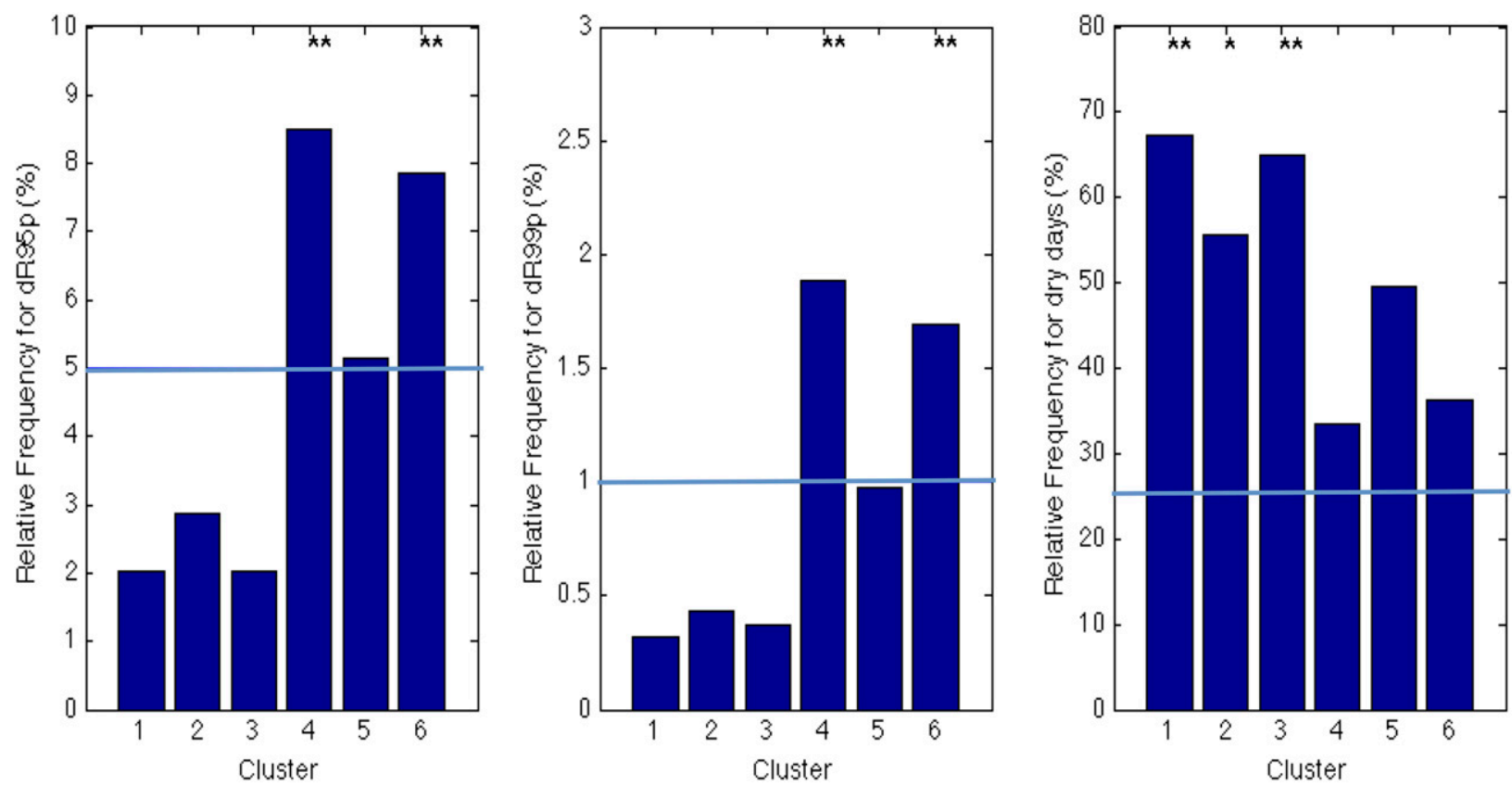

FIG. 6. Relative frequency of occurrence of each WT for days with rainfall exceeding the (left) 95th and (center) 99th percentile, and (right) for dry days. The lines indicate the corresponding climatological expected value; a double (single) asterisk indicates frequencies considered statistically different than the climatological expected value at $p<0.01(p<0.05)$.

episodes, and MCCs. From a large-scale perspective, different factors can modulate the occurrence and intensity of these local processes. In this subsection it is shown that synoptic control of extreme rainfall events by circulation regimes (i.e., that certain WTs are physically conducive to extreme events) is consistent with the known physical mechanisms reported in the literature. No attempt is made here to relate a particular WT to the occurrence of any single one of these three features, or to use them as potential predictors.

Located at a transition zone between the tropics and the extratropics, SESA's precipitation is mainly of convective nature. Convection requires low-level moisture, an unstable atmosphere, and an initial lifting force. These conditions could be achieved by the transit of baroclinic fronts (Seluchi et al. 2006) and moisture transport into SESA, especially by the SALLJ (Salio et al. 2002). Extreme rainfall can also take place in SESA by migrating MCCs (Velasco and Fritsch 1987; Ferreira et al. 2003). Long-lived MCCs can develop in sizable areas of the region (Durkee et al. 2009), for example during SALLJ events (Nicolini et al. 2002; Salio et al. 2007). Inhibition of these mechanisms produces lack of precipitation, or dry days. The hypothesis is that the aforementioned mechanisms have a representation in the daily atmospheric circulation patterns of the region, or a combination of them.

As discussed, WTs 1-3 are preferentially related to the occurrence of dry days (see Figs. 4 and 6), while WTs
4 and 6 tend to occur more frequently on extremely wet days. WT 1 is regionally associated with a positive geopotential height anomaly, whose maximum is located to the south of SESA (Fig. 7a); this anomaly promotes stability and transports moisture out of SESA toward lower latitudes, especially along the north-northeastern corner. WTs 2 and 3 (Figs. $7 \mathrm{~b}$ and $7 \mathrm{c}$, respectively) are associated with a dipolar configuration with a clear low pressure system centered about $35^{\circ} \mathrm{S}$ to the east of the region of interest; the positive pole's centroid appears in Fig. 3 to the west of the Andes for WT 2 and to the southwest of SESA for WT 3. An analysis of the low-level moisture flux divergence indicates that these circulation regimes advect more moisture out of SESA on average than into it, promoting rainfall inhibition.

On the other hand, WTs 4 and 6 (Figs. 7d and 7f) set favorable conditions for precipitation, and in some cases extremely high rainfall, through wet intrusions mainly from lower latitudes into SESA and through atmospheric instability linked to low pressure systems. It is possible to visually identify the SALLJ pattern, which is especially intense in WT 4. As discussed by Salio et al. (2002) and Nicolini and Saulo (2000), SALLJ events require certain conditions to occur, ${ }^{4}$ and therefore not every occurrence of WT 4

\footnotetext{
${ }^{4}$ Southward flow originating in tropical latitudes, greater meridional than zonal flow, and decrease of the wind speed by at least $6 \mathrm{~m} \mathrm{~s}^{-1}$ in the area enclosed by the $12 \mathrm{~m} \mathrm{~s}^{-1}$ isotach.
} 
(a) WT 1

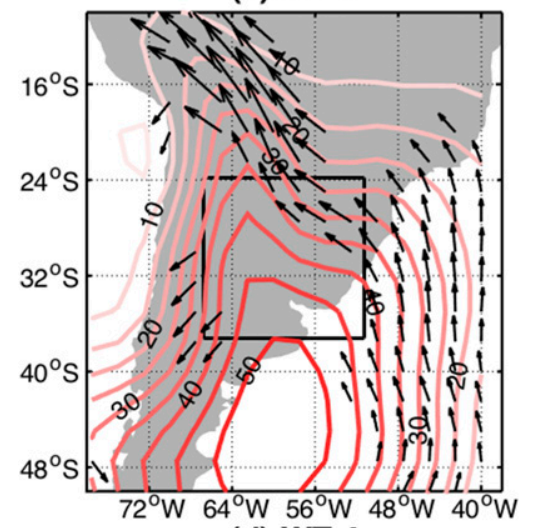

(d) WT 4

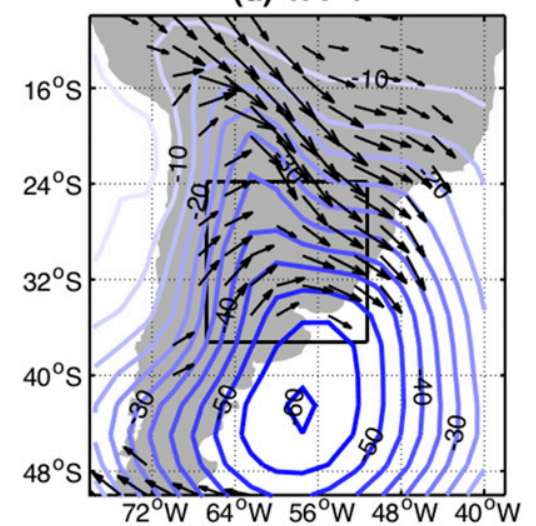

(b) WT 2

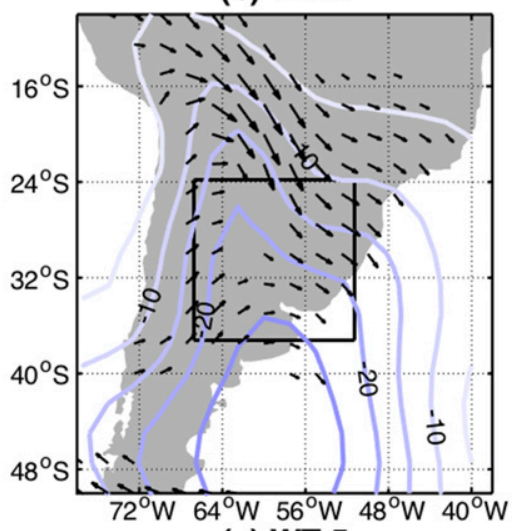

(e) WT 5

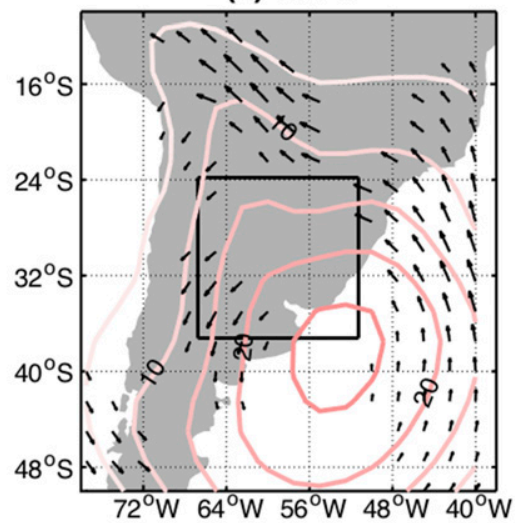

(c) WT 3

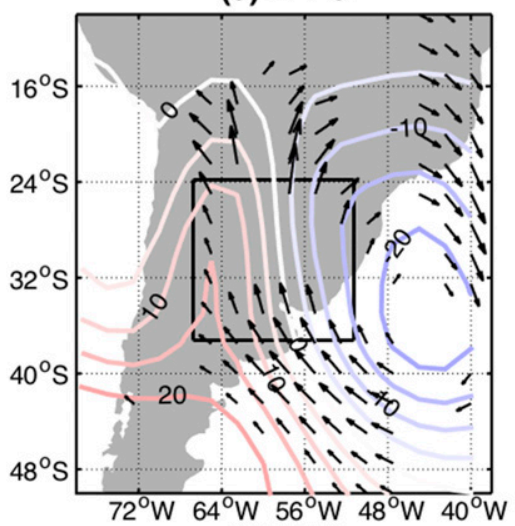

(f) WT 6

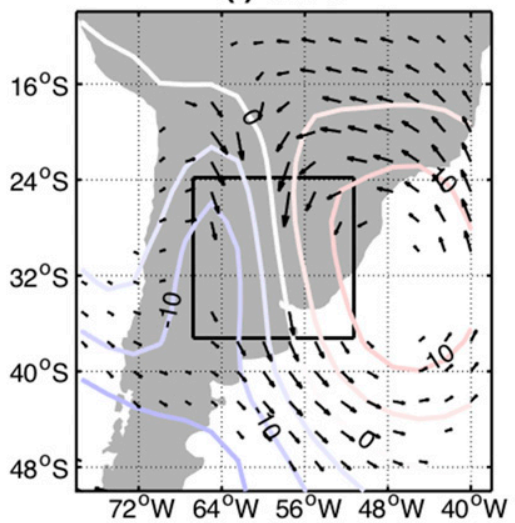

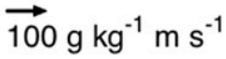

FIG. 7. Geopotential height anomalies for each WT, and their composite vertically integrated moisture flux anomalies (vectors are only shown for statistically significant fluxes). Contour lines sketch the corresponding 850-hPa geopotential height anomalies (interval: 5 gpm). The black box shows the location of SESA.

(or WT 6) occurs leads to a SALLJ event. Another possible source of moisture for the region is atmospheric rivers. It has been shown recently (Viale and Nuñez 2011) that horizontal water vapor transport tends to be more frequent between $32^{\circ}$ and $40^{\circ} \mathrm{S}$, where the height of the Andes Cordillera is generally less than $3000 \mathrm{~m}$. These events are characterized by regional negative geopotential anomalies (Viale and Nuñez 2011), in agreement with the patterns present during WTs 4 and 6 . Because of the known relationship between the SALLJ and MCCs (Salio et al. 2007), organized mesoscale convective activity takes place preferentially in the northeastern quadrant of SESA in events modulated by WT 4 . The associated cyclonic vorticity induces a northeastward moisture transport (Fig. 7d) and promotes precipitation in that sector (Fig. 4). This tends to occur over the whole SESA region in the case of WT 6 (Figs. 7f and 4). Extremely wet days are also seen without the presence of MCCs, but the conditions for convection mentioned above will still be modulated, on average, by the processes associated with WTs 4 and 6.

Although not directly related to extreme rainfall events, WT 5 is characterized by a high pressure system inducing an anticyclonic circulation in the region and enhanced moisture convergence, especially toward the southwestern corner of SESA (Fig. 7e), where positive precipitation anomalies are more frequent. As discussed before, WT 5 preferentially persists $(44 \%)$ or is a precursor of WT 6 $(\sim 30 \%)$. While WT 5 persists, moisture converges over SESA, which creates favorable conditions for precipitation events synoptically controlled by WT 6 .

The dipolar geopotential anomaly configurations and circulation patterns visible in both WT 3 and WT 6 are consistent with those associated with the continental and oceanic phases of SACZ, respectively. Several studies (Carvalho et al. 2002, 2004; Muza et al. 2009) indicate that an anomalous circulation, likely related to an enhancement of the upper-level subtropical jet and its displacement toward the western subtropical Atlantic 
Ocean, appears to be associated with the intensification of WT 6 (Fig. 7e). Moreover, the geopotential height anomaly patterns for these regimes (Figs. $3 \mathrm{c}$ and $3 \mathrm{f}$ ) are consistent with the propagation of midlatitude Rossby waves modulating the activity of SACZ, in agreement with previous studies (Ambrizzi and Hoskins 1997; Kiladis and Weickmann 1997; Liebmann et al. 1999; Carvalho et al. 2002; Van der Wiel et al. 2015).

The presence of extratropical cyclones is also evident in Figs. 3, 4, and 7. As stated before, the transition matrix (Fig. 5d) suggests the circuit $5 \rightarrow 6 \rightarrow 4 \rightarrow 2 \rightarrow 3 \rightarrow 5$, which is consistent with migration of baroclinic fronts. Seluchi et al. (2006) have shown that the transit of postfrontal anticyclones in the region (WT $5 \rightarrow$ WT 6 ) produces a poleward-pointing pressure gradient configuration. That induces geostrophic easterly flow at low levels to the west of the Andes, which is blocked by the mountains and in consequence creates a small zonal component close to the slopes (Garreaud et al. 2002) (WT $6 \rightarrow$ WT 4). Upward motions and cooling compensate the convergence of the zonal winds on the east side of the Andes. The geostrophic balance is broken near the Andes and southerly winds develop, increasing cold advection (WT $2 \rightarrow$ WT 3 ). This, in turn, cools the lower troposphere, promoting the northward propagation of the front.

It is expected that the different features related to extreme precipitation in SESA could interact with each other, at least some of the time. Indeed, Salio et al. (2002) have discussed the relationship between SACZ and the SALLJ, which seems to be a frequent component of the southern flow visible both in WT 4 and WT 6 . All of this suggests that extreme precipitation is not only linked to the daily occurrence of a particular circulation patterns, but may also be related to a sequence of WTs: joining the synoptic letters into "words."

A study of extreme events in terms of circulation regimes and their evolution in time and space indeed provides a better understanding of the physical mechanisms, including how and when they are related to each other. To explore the potential predictability of these events, it is necessary to analyze the additional relationship between these atmospheric circulation regimes and potential sources of predictability in the large-scale climate.

\section{Weather types and climate drivers}

The role of large-scale climate drivers is discussed in this section, both at seasonal and subseasonal scales.

\section{a. Seasonal scale}

Previous studies (Cazes-Boezio et al. 2003; Carvalho et al. 2004; Almeira and Scian 2006; Barreiro 2010; Muza et al. 2009) have shown that extreme rainfall events at seasonal scale tend to be more frequent during persistent SST anomaly patterns, both in the Pacific and the Atlantic Oceans. On the other hand, at hemispheric scale the WTs show circumpolar atmospheric wavelike patterns with an imprint of zonal wavenumbers 2-3 (Fig. 3), typical of the SAM. This equivalent barotropic mode is the most important mode of variability in the high latitudes of the Southern Hemisphere's atmospheric circulation (Marshall 2003), and it is known to impact SESA's precipitation all year around and even modulate ENSO's signal on rainfall in the region (Silvestri and Vera 2003). The question that arises is how these SST patterns and planetary waves are related to each WT, and if it is possible to exploit these relations as robust sources of potential predictability.

A first step is to identify which SSTA spatial patterns are associated with each circulation regime. Composites of SST anomalies (Fig. 8) for the austral summer seasons in which each particular circulation regime frequency exceeds the 80th percentile of the 31-season frequency distribution show El Niño-like SSTA signatures for WTs 2, 4, and 6, whereas La Niña-like SSTA configurations appear for WTs 3 and 5. A high frequency of occurrence of WT 1 appears to be related to the positive phase of the AMM and a tripolar SSTA configuration in the Pacific. An AMM SSTA pattern also appears to be present for years with high frequency of occurrence of WT 3. SAD-like SSTA patterns, in turn, tend to be related to WTs 2,4 , and 6 .

More generally, in order to explore the role of largescale physical drivers in the predictability of extreme events in SESA through the modulation by the different WTs, anomaly lag correlations ( $0-2$ months before November) were computed between the frequency of occurrence of each regime and four different indices: Niño-3.4, AMM, SAD, and SAM.

The highest values of significant correlations for several potential predictors were found for lead time 0 (November; see Fig. 9). The results for the lead times considered are summarized in Table 2, which provides potential seasonal predictors for all the WTs.

It was found that WT 1 significantly correlates with the positive phase of AMM for lead times of $-2,-1$, and 0 months and the positive phase of SAM for lead time of -1 month. The positive phases of both SAM and SAD are good predictors for higher seasonal frequency of WT 2. WT 3 was found to be the circulation pattern with the highest number of predictors at multiple lead times: significant correlations were found for La Niña and the positive phases of AMM, SAD, and SAM. Higher frequency of WT 4, in turn, is only linked to 

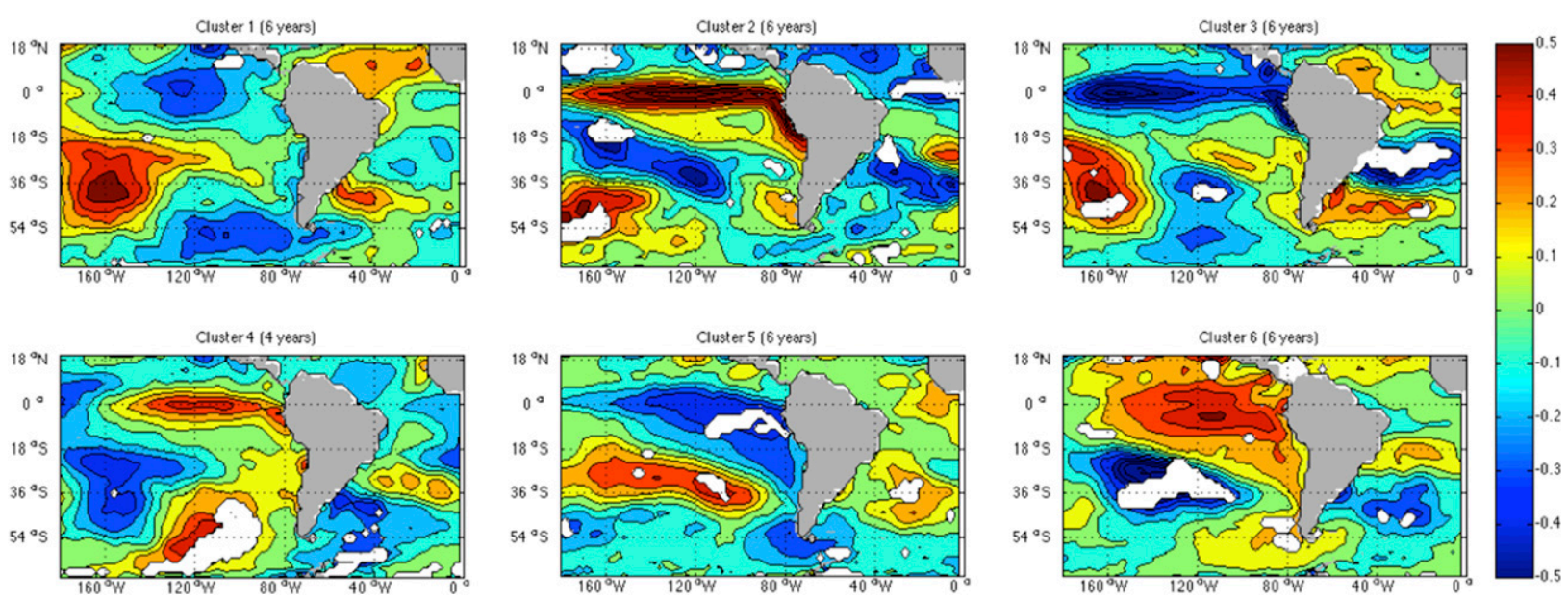

FIG. 8. Composites of SST anomalies $\left({ }^{\circ} \mathrm{C}\right)$ for austral summers in which regime frequency exceeds the 80 th percentile of the 31 -season frequency distribution. The number of summers obtained for each regime is given in parentheses. Areas in white are not statistically significant at $p<0.05$ (hypergeometric test).

negative phases of SAM. Something similar happens with WT 5, but only for December's values of SAM, during the negative phase. Finally, the frequency of WT 6 was found to be significantly correlated to El Niño and negative phases of AMM, SAD, and SAM. WT 3 was found to be significantly correlated to La Niña and positive phases of AMM, SAD, and SAM.

Overall, there is no clear distinction between the predictors in terms of lead times, but there is consistency between the quasi-inverse phases of the WT and the phase inversion in the associated seasonal predictors: it is clear that positive phases of AMM, SAD, and SAM are preferentially associated with higher frequency of occurrence of WTs 1-3, while the negative phases of the same climate drivers tend to increase the frequencies of WTs 4-6. The fact that ENSO has an impact on the seasonal frequency of circulation regimes for WTs 3 and 6 is also consistent with the discussion presented in section 4 , and with the results reported in the literature on modulation of extreme events (Cazes-Boezio et al. 2003; Carvalho et al. 2004; Almeira and Scian 2006; Barreiro 2010; Muza et al. 2009).

For potential predictability, it is useful that the circulation patterns are ascribed to climate phenomena because that means that, in the best-case scenario, several sources could be used simultaneously to forecast the frequency of extreme events, even if some of the drivers are in their neutral or weak phase. In particular, in neutral ENSO years, AMM and SAD could still be potential sources, because although ENSO could modulate them, their own variability has a significant impact (e.g., Muza et al. 2009). Conversely, considering only one predictor may provide only a partially successful forecast, especially when other drivers act simultaneously in a reinforcing or attenuating way (see, e.g., Cazes-Boezio et al. 2003; Silvestri and Vera 2003; Barreiro 2010).

\section{b. Subseasonal scale}

To determine associations between circulation regime frequencies and subseasonal-scale drivers, the relative frequency of WT occurrence was computed during both the eight phases of MJO as defined by Wheeler and Hendon (2004) (Fig. 10) and the positive and negative phases of the 10-100-day bandpass-filtered SACZ index (Carvalho et al. 2004, 2011) (Fig. 11). Relationships with the large-scale index for the South American monsoon (LISAM; Carvalho et al. 2011) were also explored, but the results were not statistically significant. These figures permit to identify phases and lead times in the potential predictors that could be used in statistical prediction models; the attention is focused in the sections of the plots with the darker red colors (see the methodology section for details).

The analysis performed on the MJO (Fig. 10) suggests some potential predictability for dry days at intraseasonal scale, as the MJO phases 6-7, when convection is enhanced over the western Pacific, significantly lead WT 3 by up to 14 days in advance. The relationship between MJO and the other WTs is not as clear as in the WT 3, but some information can be deduced from this analysis. For example, MJO phases 2-3, related to convection over the Indian Ocean, lead WT 6 by up to 8 days in advance, suggesting potential predictability for extremely wet days associated with moisture fluxes from the tropics into SESA, typically via the SALLJ.

On the other hand, there seems to be a strong relation between the SACZ phase and all the WTs (Fig. 11), but it is especially clear for WTs 3, 5, and 6 . The longest lead time ( $\sim 13-14$ days) was found for the 

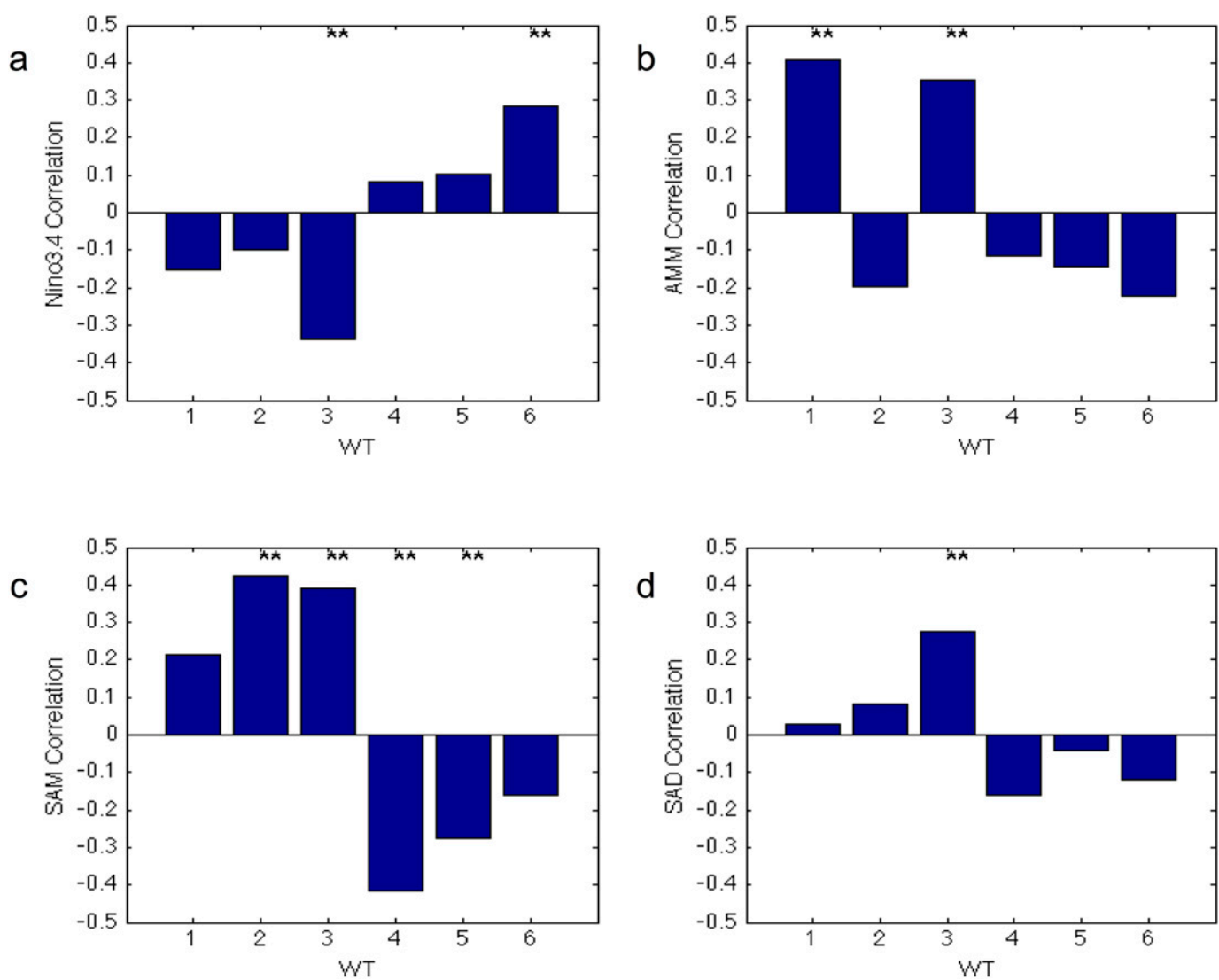

FIG. 9. Anomaly correlation between the number of days in each cluster (WT) in each DJF season, and the value of the (a) El Niño-3.4 index, (b) AMM, (c) SAM, and (d) SAD, for November. Two asterisks denote statistical significance at the two-sided $p<0.05$ confidence level, calculated using a bootstrap resampling method in which the time series were randomized 1000 times.

negative phase of SACZ and WT 1. Its positive phase presents a continuous signal for WT 3 with lead times of approximately one week (Fig. 11). This suggests predictability for dry days in SESA with short (0-7 days, positive phase) to intermediate (13-14 days, negative phase) lead times. The fact that WT 3 shows a clear relation to SACZ is consistent with its precipitation patterns (Fig. 4), where the typical dipolar rainfall configuration associated with SACZ (Carvalho et al. 2004) is visible for this regime.

In contrast, weather types related to extremely wet days are associated with the negative phase of SACZ up to a week before the occurrence of the WT, with lead times of approximately 3-6 days for WT 6 and 2-8 days for its precursor, WT 5 (Fig. 11). The positive phase of SACZ also tends to lead WT 4 by approximately

TABLE 2. Some sources of potential predictability at subseasonal-to-seasonal scales for the frequency of occurrence of each WT. The exponent indicates the phase of the index (positive and negative phases denoted by the plus and minus signs, respectively, and phase number for MJO), while the subscript values indicate, in decreasing order, the larger lead times of the maximum signal found (in months previous to November for ENSO, AMM, SAD, and SAM; in days previous to the occurrence of the WT for MJO and SACZ). A colon is used to indicate sequences of days ranging between the specified lags.

\begin{tabular}{|c|c|c|c|c|c|c|}
\hline & WT 1 & WT 2 & WT 3 & WT 4 & WT 5 & WT 6 \\
\hline Seasonal drivers & $\begin{array}{l}\mathrm{AMM}_{-2,-1,0}^{+} \\
\mathrm{SAM}_{-1}^{+}\end{array}$ & $\begin{array}{l}\mathrm{SAM}_{0,-2}^{+} \\
\mathrm{SAD}_{-2,-1}^{+}\end{array}$ & $\begin{array}{l}\mathrm{ENSO}_{-1,0,-2}^{-} \\
\mathrm{AMM}_{0,-1}^{+} \\
\mathrm{SAD}_{0,-2}^{+} \\
\mathrm{SAM}_{0}^{+}\end{array}$ & $\mathrm{SAM}_{0,-2}^{-}$ & $\mathrm{SAM}_{0}^{-}$ & $\begin{array}{l}\mathrm{ENSO}_{-2,-1,0}^{+} \\
\mathrm{AMM}_{-2,-1}^{-} \\
\mathrm{SAD}_{-1,-2}^{-} \\
\mathrm{SAM}_{-2}^{-}\end{array}$ \\
\hline Subseasonal drivers & $\begin{array}{l}\mathrm{MJO}_{-9}^{5} \\
\mathrm{SACZ}_{-14,-13}^{-}\end{array}$ & $\mathrm{SACZ}_{-8,-4}^{-}$ & $\begin{array}{l}\mathrm{MJO}_{-14:-11}^{6} \\
\mathrm{MJO}_{-13:-4}^{7} \\
\mathrm{SACZ}_{-6:-3}^{+}\end{array}$ & $\mathrm{SACZ}_{-11}^{+}$ & $\begin{array}{l}\mathrm{MJO}_{-12}^{5} \\
\mathrm{MJO}_{-10:-5}^{6} \\
\mathrm{SACZ}_{5}^{-}\end{array}$ & $\begin{array}{l}\mathrm{MJO}_{-8}^{2} \\
\mathrm{MJO}_{-6:-2}^{3} \\
\mathrm{SACZ}_{-6,-4}^{-}\end{array}$ \\
\hline
\end{tabular}



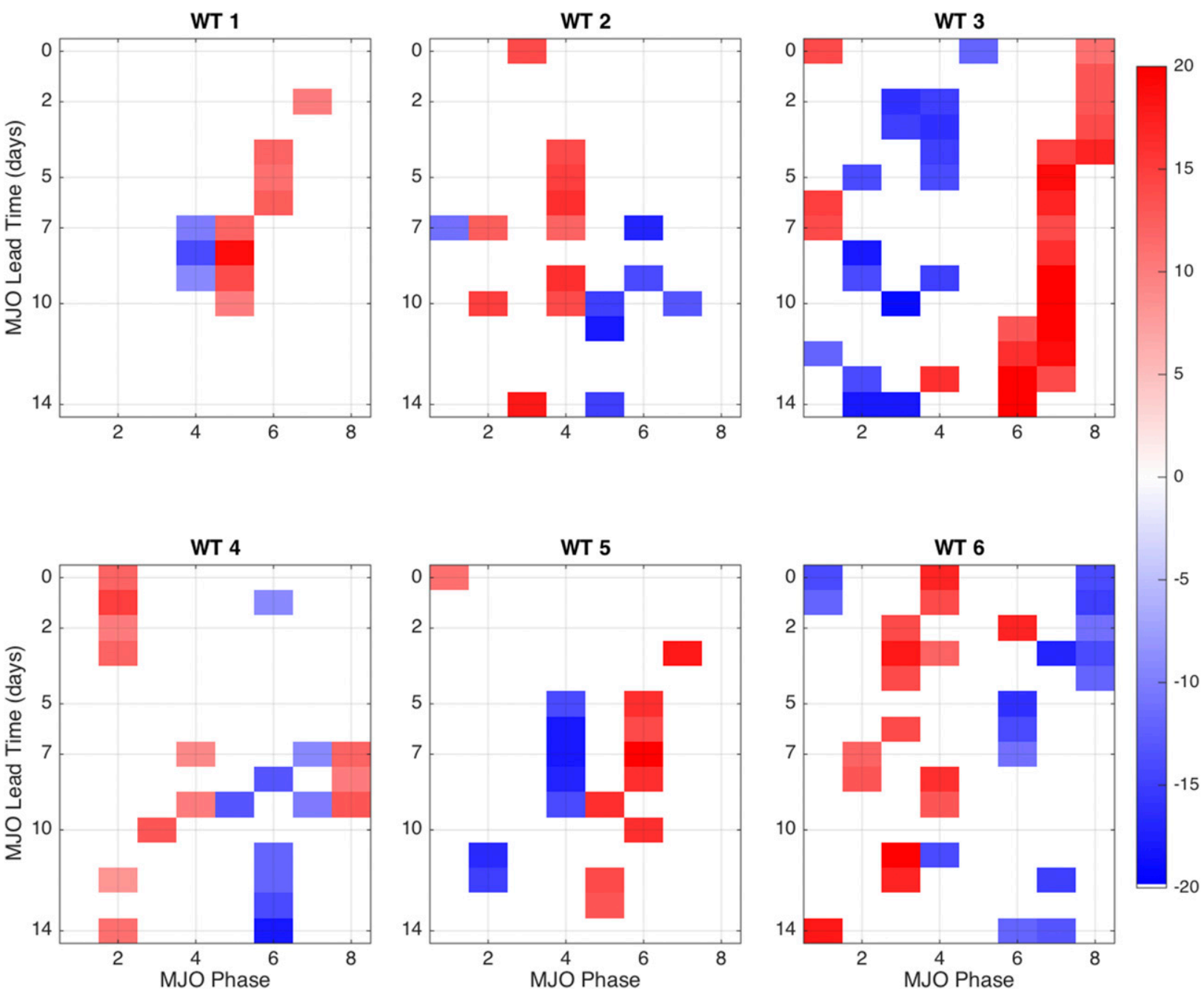

FIG. 10. Anomalous percentage of occurrence (see color bar) of each WT for each phase of the MJO (DJF 1979-2010). The ordinate gives the number of days that the MJO phase precedes each WT, from 0 (simultaneous) to 14 days. Colored tiles are significant at $p<0.05$ confidence level, obtained using a bootstrapping method resampling 1000 times.

10-11 days. As discussed before, SACZ and the SALLJ are related to each other, and this is consistent with the behavior of the moisture fluxes (Fig. 7) and the precipitation patterns (Fig. 4). The lead times sketched in Fig. 11 for WTs 5 and 6 are also coherent with the transition probability matrix (Fig. 5d): WT 5 tends to persist or to be followed by WT 6 .

Again, predictability results are summarized in Table 2. In the next section these results are summarized and discussed.

\section{Discussion}

The picture that arises from the analysis performed in the previous sections indicates that, at seasonal scale, planetary waves and persistent SST configurations are statistically related to synoptic control of occurrence of extreme events. At seasonal scale and based on their mean phases for November, the climate drivers show a differential impact on how many WTs they influence. SAM has an impact on all the synoptic circulation types studied, its positive phase being associated with WTs that are frequently linked to dry extreme events (WTs 1-3), while wet ones (WTs 4-6) tend to be more frequent when SAM is in its negative phase. The most important Atlantic SST modes found to affect the circulation regimes over SESA at seasonal scales are the transequatorial (AMM) and the southern zonal (SAD) modes. It was also found that positive phases of AMM are linked to dry extreme events (WTs 1 and 3) and negative phases to extremely wet days (WT 6). The same relationship is exhibited by SAD for days with extremely high rainfall, and its positive phase, associated with dry days, was shown to be statistically linked to circulation regimes related to low pressure systems to the east of SESA (WTs 2 and 3). ENSO, in turn, modulates dry spells through 

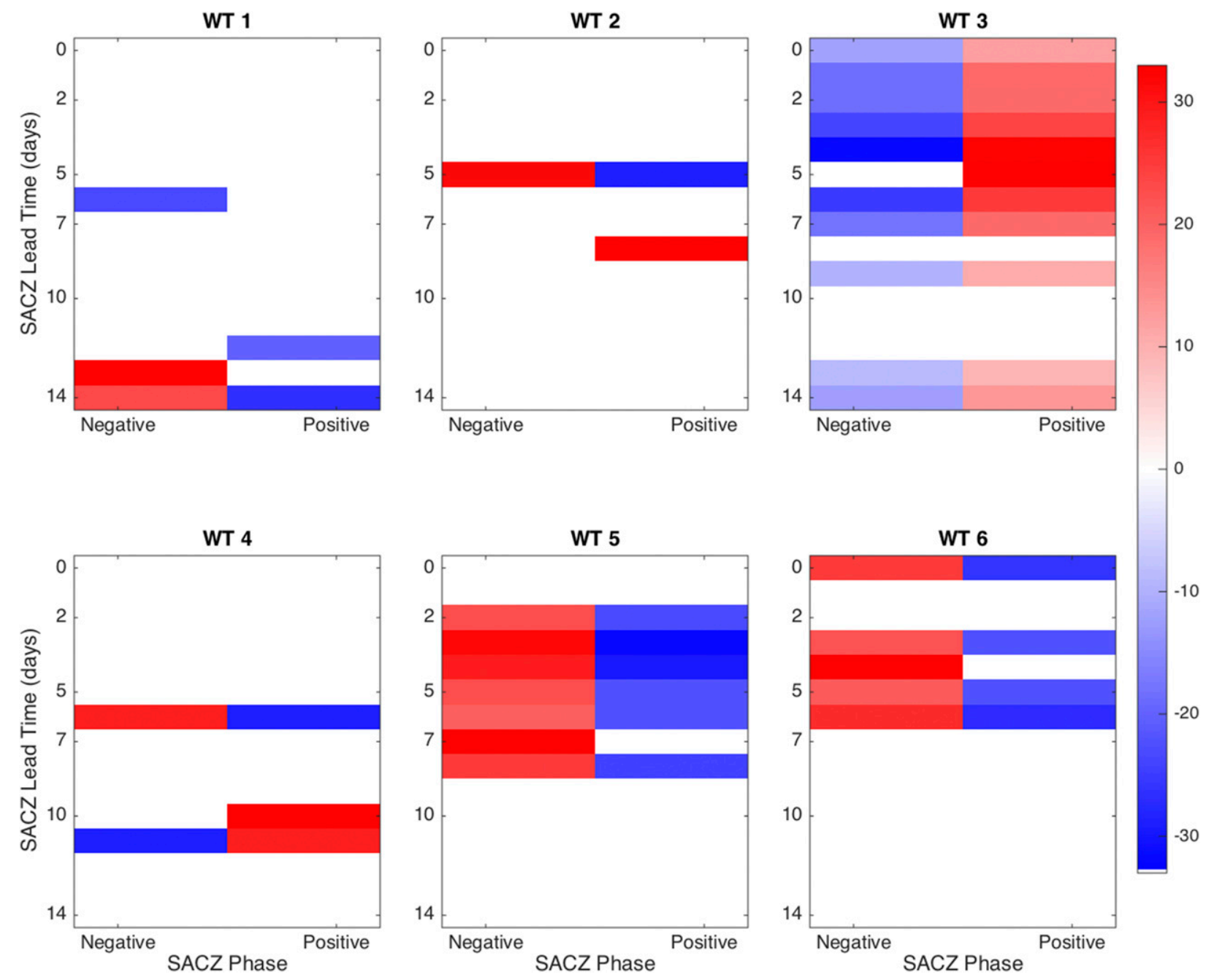

FIG. 11. As in Fig. 10, but for the positive and negative phases of the SACZ index.

WT 3 during La Niña and wet extreme events through WT 6 during El Niño.

At subseasonal scale MJO phases associated with enhanced convection in the western Pacific tend to be present up to about 14 days in advance of the dry events (WT 3) in SESA, while phases related to enhanced convection over the Indian Ocean tend to occur between 5 and 8 days in advance of extremely wet events (WT 6). Similarly, SACZ has a tendency to be in its positive phase up to one week before days with no precipitation (WTs 2 and 3) and in its negative phase up to a week before extremely wet days (WTs 4-6). The opposite phases tend to be present for lead times of approximately 10-14 days: negative for dry days (WT 1) and positive for change for wet days (WT 4).

Physically, all these large-scale climate drivers control the occurrence of extreme rainfall through modulation of the passage of cyclonic baroclinic systems (extratropical cyclones) and the associated circulation anomalies, modifying the moisture transport, convergence, and presence of MCCs over SESA, in agreement with previous studies already referenced in this work. The different mechanisms in the local picture cannot, in general, be traced to an independent larger-scale climate driver acting on its own, but rather to a complex interaction between them. It is known (Mo and NoguesPaegle 2001) that during El Niño episodes meridionally propagating Rossby waves originating from tropical heat sources are deflected in high latitudes, modulating SAM (Silvestri and Vera 2003), causing anomalous circulations along southern South America, and even modifying SSTA patterns in the Atlantic through windevaporation-SST feedbacks (Zhou and Carton 1998). It has also been shown that there exists an interaction between ENSO and AMM, modulated by wind-forced equatorial Kelvin waves and a delayed negative feedback from western boundary reflections of wind-forced 
TABLE 3. "Constructive" seasonal (SON) and subseasonal (days before the occurrence of the WT) conditions for occurrence of wet and dry extreme events during DJF. Note that the actual lead times are different for different indices (see Table 2).

\begin{tabular}{|c|c|c|c|c|c|c|c|}
\hline \multirow{2}{*}{$\begin{array}{c}\text { Most likely } \\
\text { event }\end{array}$} & \multicolumn{4}{|c|}{ Seasonal index (phase) } & \multicolumn{2}{|l|}{ Subseasonal index (phase) } & \multirow[b]{2}{*}{ Example } \\
\hline & ENSO & AMM & SAD & SAM & MJO (location of maximum convection) & SACZ & \\
\hline $\begin{array}{l}\text { Extremely wet } \\
\text { days }\end{array}$ & + & - & - & - & 2 and 3 western Pacific (10-12 days) & $-(<7$ days $)$ & 1991/92 \\
\hline $\begin{array}{l}\text { Extremely dry } \\
\text { days }\end{array}$ & - & + & + & + & 6 and 7 Indian Ocean (4-14 days) & $+(<7$ days $)$ & 2008/09 \\
\hline
\end{tabular}

Rossby waves (Foltz and McPhaden 2010). Moreover, the Matsuno-Gill-type baroclinic structure associated with AMM has been proposed to be related to meridionally propagating Rossby waves extending into the extratropical South Atlantic, forcing reverse SST anomalies through changes in evaporation due to anomalous circulation at the surface (Trzaska et al. 2007), and inducing a counterclockwise migration of SSTA in the Atlantic basin that is consistent with SAD (Nnamchi et al. 2011). At subseasonal scale, MJO and SACZ also interact with each other and with the larger-scale seasonal drivers as the ones mentioned above (Muza et al. 2009; Carvalho et al. 2011).

\section{a. Cross-time scale interactions}

The big picture just described suggests that although a strong "background signal" may be established by a climate driver (e.g., ENSO), interactions with signals from other drivers even at different time scales may amplify or attenuate that signal. Since extreme rainfall events are very sensitive to what may happen over short time scales (i.e., a few hours to a few days), it is especially important to address the constructive or destructive interference-as in elementary wave physics-that the subseasonal signals may add to the background seasonal signal. As an example, consider the case of favorable conditions for extremely wet events set by constructive interference of seasonal-scale drivers, and then on top of that assume that the MJO or SACZ (or both) are in a phase conducive to no rain (see Table 3 ) for a particular set of days within DJF. The most likely result is a decrease in the frequency (or even absence, depending on the relative intensity of the synoptic control) of extremely wet days for the set of days of interest.

This discussion leads to conjecture that in the most general case, the modulation of extreme rainfall events by recurrent synoptic circulation regimes takes place by means of simultaneous or time-lagged interference of all the different potential predictors. Each has its own specific weight and spatial and temporal scale of impact. This will be referred to as "cross-time scale interference." In consequence, an optimal set of multiscale predictors should be considered in order to provide more accurate information to decisionmakers.

One way to provide a simple illustration of the crosstime scale interference is to compute the conditional probabilities of occurrence of WTs given particular phases of potential predictors at different time scales. It will be shown in the companion paper of this study that some probabilities of WT occurrence as a function of MJO phases significantly differ between El Niño and La Niña years.

\section{b. Setting the stage for a prediction model: Predictive state vectors}

Following the previous discussion, it is useful to summarize the constructive seasonal conditions, mostly expressed here in terms of mean phases for each mode of variability, that will enhance the likelihood for a high frequency of occurrence of extreme rainfall events in SESA. For September-November (SON), the negative phase for all AMM, SAD, and SAM modes and the positive phase of ENSO are favorable for extremely wet days. The opposite would be the case for extremely dry days. "Constructive" here means that if all the analyzed climate drivers fulfilled these necessary conditions in their corresponding time window, considering their different lead times, then an extremely wet or extremely dry season would be likely in DJF. Although these constructive configurations are extreme conditions, both in the sense that 1) they are opposites in the spectrum of possible combinations of states conducive to extreme rainfall and 2) they occur only once in the entire period considered here, their analysis is important to understand the more common "intermediate" states (see below). As presented in Table 3 only the phases of the climate drivers are used, but it is possible to generalize these raw "predictive state vectors" to include index magnitudes.

This idea of predictive state vectors is consistent with prediction methodologies involving principal component regressions and canonical correlation analysis (Mason and Baddour 2008). It could also be used as a rudimentary early warning system for extreme rainfall events in SESA. However, unless magnitudes are considered in addition to phases, such a system supplies no 
TABLE 4. Mean SON phases (or raw "predictive state vectors") of the seasonal drivers considered in this study and most frequent extreme events (MFE) observed for each DJF season. Phases are indicated with a positive or a negative sign for the SON season. For ENSO, "N" indicates a neutral year, and "S", "M," and "W" indicate strong, moderate, and weak events, respectively. Boldfaced years show ideal conditions for occurrence of extremely wet and dry events (Table 3 ).

\begin{tabular}{lllccc}
\hline \hline Season & MFE & ENSO & AMM & SAD & SAM \\
\hline $1980 / 81$ & Wet & N & + & - & - \\
$1982 / 83$ & Wet & + S & - & + & - \\
$1983 / 84$ & Wet & - W & - & - & + \\
$1987 / 88$ & None & + S & + & + & + \\
$1989 / 90$ & Wet & N & + & + & + \\
$\mathbf{1 9 9 1 / 9 2}$ & Wet & + M & - & - & - \\
$1997 / 98$ & Wet & + S & - & + & - \\
$2004 / 05$ & Dry & + W & + & + & - \\
$2007 / 08$ & Dry & - M & + & + & - \\
$\mathbf{2 0 0 8 / 0 9}$ & Dry & - W & + & + & + \\
$2009 / 10$ & Dry/wet & + M & + & - & - \\
\hline
\end{tabular}

information about intensities; it only discerns if there will be higher-than-normal wet or dry events in a particular DJF season.

Indeed, the analysis of the seasonal component of these state vectors for several years (Table 4) reveals that 1991/92 and 2008/09 are concrete examples of the "constructive" conditions discussed earlier for seasons characterized by a higher-than-normal number of extremely wet and dry days (Fig. 2), respectively, providing the expected outcome. In intermediate states (all other years) the interaction is more complex, but the selection rule for the outcome seems to be defined by the agreement of at least two signals with the conditions discussed earlier (Table 3), especially if these two climate drivers are ENSO and AMM, and considering that in weak ENSO years the other signals seem to have a higher relative weight in the final output (e.g., 1980/81, 1983/84, and 2004/05) than in moderate-to-strong ENSO years, as one should expect.

Although the conjecture of multiscale interference indicates that the climate drivers affecting a region are always interacting with each other, in the example above higher-frequency climate drivers were not considered in order to explain the occurrence of extreme rainfall in SESA. Furthermore, there is a special case in the list of events considered (Table 4) in which the subseasonal component of the potential predictor set plays a key role. The seasonal component of the predictive vector state for the season 1989/90 is (following a typical quantum mechanics notation and with the phases appearing in the same order than the indices in Table 3)

$$
|1990\rangle_{\text {seasonal }}=|N,+,+,+\rangle .
$$

Based purely on the seasonal conditions and the selection rules discussed earlier, the expected outcome would be "higher-than-normal frequency of extreme dry days"but that is not what happened (Fig. 2). An analysis of the phases of both subseasonal potential predictors for the corresponding DJF season shows that there were a large number of days in the period in which MJO presented conditions conducive to extremely wet days (phases 2 and 3 were present during 21 December11 January and 18-26 February, and phases 6 and 7 were only present during 5-8 December and 24 January2 February); moreover, the SACZ remained in a negative phase for a total of 73 days (out of 90) in the season, mostly continuous. This is a clear example about how the subseasonal drivers can interfere with the seasonal signal and why it is important to consider the whole set of multiscale potential predictors. It can also be shown that season 2009/10 had a higher-than-normal frequency of both dry and wet extreme rainfall events for similar reasons: favorable conditions for wet days associated with the phases of ENSO, SAD, SAM, and SACZ, and conditions for dry days related to AMM and MJO.

A simple conceptual model using only the phases of the potential predictors to represent the complexities of the multiscale interferences that take place between them is not adequate to make accurate predictions. More complex models using the principle of cross-time scale interference must be explored. As indicated earlier, such models could also be used to build indicators for early warning systems that could be easily implemented by local or regional climate service providers (see, e.g., Muñoz et al. 2010, 2012). For example, a complete subseasonal-to-seasonal predictive state vector conducive to extremely wet days for a certain period within a particular season DJF in SESA is (Table 3)

$$
|\mathrm{DJF}\rangle_{\mathrm{s} 2 \mathrm{~s}}=|+,-,-,-,(2,3),-\rangle
$$

\section{Conclusions}

With a focus on the southeastern South America region for DJF, a season known to be more complex than others in terms of rainfall predictability in the region (Cazes-Boezio et al. 2003; Barreiro 2010), this work analyzed recurrent synoptic weather types, extreme events, and climate drivers to identify relationships associated with both wet and dry extreme rainfall events for DJF. The results indicate that subseasonal-toseasonal-scale climate drivers interact to modulate the occurrence of the circulation regimes that are conducive to extreme rainfall events in SESA, via their 
imposed synoptic control on mesoscale physical features (Table 2).

The circulation regimes represent the daily realization of regional and local physical mechanisms, some of them directly involved in the occurrence of extreme rainfall through the transit of extratropical cyclones, heat and moisture advection, and convective mesoscale complexes. The analysis of the relationship between the circulation regimes and climate drivers indicates that the seasonal frequency of extreme events is modulated by the phases and particular configurations of ENSO, AMM, SAD, and SAM in the preceding months (September-November) and further modulated by the phases of MJO and SACZ, generally during the previous 3-14 days (Table 3). Moreover, the MJO and/or SACZ could sometimes dominate the interannual signal.

An integrated cross-time scale approach is proposed for extreme events prediction, the first of its kind for the region. The rationale is that since different climate drivers have their own imprint in the extreme rainfall characteristics (e.g., frequency, intensity, and location) and they also tend to interact with each other, considering a reduced set of the required predictors leads to inferior diagnostic and forecast information. The idea of using cross-time scale interference between climate drivers, although not new (see, e.g., Meehl et al. 2009; Greene et al. 2011; Goddard et al. 2014), has been explored more at longer time scales, and it is not yet common in statistical prediction of subseasonal-to-seasonal events. Modern dynamical models, by their own nature, consider this integrated approach, but their present skill for extreme rainfall events and even the representation of large-scale climate drivers still has room for improvement.

The weather type approach used in this work presents several advantages with respect to other methods. First, it helps to better understand the cross-time scale physical processes behind the occurrence of extreme events by linking large-scale climate drivers with particular daily synoptic configurations that are conducive to those extremes. It permits one to identify potential sources of predictability at different time scales. And most importantly, since the weather types are a realization of the available states of the system, they represent a nearly complete set of potential predictors, thus simplifying the task of identifying all the possible potential predictors. In other words, the WTs constitute a particular "alphabet" to describe all possible synoptic states in the region, and the particular sequences of this alphabet (i.e., "words") may be related to the occurrence of extremes. The use of cryptographic algorithms to decipher these relationships could be worth pursuing, in some kind of "atmospheric cryptography" approach.

At subseasonal scale, the WT approach also provides a coherent weather generator method to produce daily sequences of precipitation (Richardson 1981; Racsko et al. 1991) in a way that is physically consistent with the observed behavior of the circulation regimes and how these are modulated by the climate drivers.

Since dynamical models generally do a better job representing atmospheric circulation than precipitation patterns and characteristics of extreme rainfall events, the study of simulated WTs could shed light on the particular aspects of the dynamical models that must be improved in order to increase their performance in representing and predicting extreme events. Simulated weather types could also be used as potential predictors for extreme rainfall events in statistical models, via a model output statistics (MOS) approach. Since the WTs represent a filtered version of the physical field used to define them (e.g., 850-hPa geopotential height anomalies), the predictive skill is expected to be higher.

The methodology employed here is general and can be used for other regions not only to better understand the mechanisms associated with extreme rainfall events, but also to analyze the association of these structures with regional and large-scale physical features at play in these other regions, thus helping to identify potential sources of predictability at different scales.

A companion paper, representing the second part of this work, will explore the predictability of extreme rainfall events for the region under study using statistical models considering the cross-time scale interactions and potential predictors found by this study.

Acknowledgments. The authors are grateful to Simon Mason, Mike Tippett, and Tony Barnston for useful discussions regarding the statistical components of this paper, to Leila Carvalho for providing the data of both SACZ and LISAM indices, and to three anonymous reviewers whose insightful comments helped improve the original manuscript. This work was supported by the National Science Foundation project AGS1049066 (SESA project), and it is part of Muñoz's doctoral thesis as Faculty Fellow at the Department of Earth and Environmental Sciences (DEES) of Columbia University. Robertson and Kushnir were supported by MURI Grant N00014-12-1-0911. Muñoz thanks the Sustainability Research Institute (SRI) at the University of Leeds for hosting him; during that visit part of this manuscript was written. The authors declare no conflict of interests. 


\section{REFERENCES}

Alessandro, A. P., 1996: Situación sinóptica asociada a la sequía del invierno de 1995. Rev. Geofis., 45, 125-143.

—_, 2001: Long waves around South America and precipitation in Argentina. Meteor. Appl., 8, 85-95, doi:10.1017/ S1350482701001074.

Almeira, G. J., and B. Scian, 2006: Some atmospheric and oceanic indices as predictors of seasonal rainfall in the Del Plata Basin of Argentina. J. Hydrol., 329, 350-359, doi:10.1016/ j.jhydrol.2006.02.027.

Ambrizzi, T., and B. J. Hoskins, 1997: Stationary Rossby-wave propagation in a baroclinic atmosphere. Quart. J. Roy. Meteor. Soc., 123, 919-928, doi:10.1002/qj.49712354007.

Barnston, A. G., and M. K. Tippett, 2014: Climate information, outlooks, and understanding-Where does the IRI stand? Earth Perspect., 1, 20, doi:10.1186/2194-6434-1-20.

,,-- M. L. L'Heureux, S. Li, and D. G. DeWitt, 2012: Skill of real-time seasonal ENSO model predictions during 2002-11: Is our capability increasing? Bull. Amer. Meteor. Soc., 93, 631651, doi:10.1175/BAMS-D-11-00111.1.

Barreiro, M., 2010: Influence of ENSO and the South Atlantic Ocean on climate predictability over southeastern South America. Climate Dyn., 35, 1493-1508, doi:10.1007/s00382-009-0666-9.

Bettolli, M. L., M. Vargas, and O. C. Penalba, 2009: Soya bean yield variability in the Argentine Pampas in relation to synoptic weather types: Monitoring implications. Meteor. Appl., 16, 501-511, doi:10.1002/met.148.

, O. C. Penalba, and W. M. Vargas, 2010: Synoptic weather types in the south of South America and their relationship to daily rainfall in the core crop-producing region in Argentina. Aust. Meteor. Oceanogr. J., 60, 37-48.

Carvalho, L. M. V., C. Jones, and B. Liebmann, 2002: Extreme precipitation events in southeastern South America and large-scale convective patterns in the South Atlantic convergence zone. J. Climate, 15, 2377-2394, doi:10.1175/1520-0442(2002)015<2377: EPEISS $>2.0 . \mathrm{CO} ; 2$.

,-- , and -2004 : The South Atlantic convergence zone: Intensity, form, persistence, and relationships with intraseasonal to interannual activity and extreme rainfall. J. Climate, 17, 88108, doi:10.1175/1520-0442(2004)017<0088:TSACZI >2.0.CO;2.

—, A. E. Silva, C. Jones, B. Liebmann, P. L. Silva Dias, and H. R. Rocha, 2011: Moisture transport and intraseasonal variability in the South America monsoon system. Climate Dyn., 36, 1865-1880, doi:10.1007/s00382-010-0806-2.

Cassou, C., 2008: Intraseasonal interaction between the MaddenJulian oscillation and the North Atlantic Oscillation. Nature, 455, 523-527, doi:10.1038/nature07286.

Cazes-Boezio, G., A. W. Robertson, and C. R. Mechoso, 2003: Seasonal dependence of ENSO teleconnections over South America and relationships with precipitation in Uruguay. J. Climate, 16,1159-1176, doi:10.1175/1520-0442(2003)16<1159: SDOETO $>2.0 . \mathrm{CO} ; 2$.

Chen, M., W. Shi, P. Xie, V. B. S. Silva, V. E. Kousky, R. W. Higgins, and J. E. Janowiak, 2008: Assessing objective techniques for gauge-based analyses of global daily precipitation. J. Geophys. Res., 113, D04110, doi:10.1029/2007JD009132.

Durkee, J. D., T. L. Mote, and J. M. Shepherd, 2009: The contribution of mesoscale convective complexes to rainfall across subtropical South America. J. Climate, 22, 4590-4605, doi:10.1175/ 2009JCLI2858.1.

Ferreira, R. N., T. M. Rickenbach, D. L. Herdies, and L. M. V. Carvalho, 2003: Variability of South American convective cloud systems and tropospheric circulation during JanuaryMarch 1998 and 1999. Mon. Wea. Rev., 131, 961-973, doi:10.1175/1520-0493(2003)131<0961:VOSACC > 2.0.CO;2.

Foltz, G. R., and M. J. McPhaden, 2010: Interaction between the Atlantic meridional and Niño modes. Geophys. Res. Lett., 37, L18604, doi:10.1029/2010GL044001.

Garreaud, R. D., J. A. Rutllant, and H. Fuenzalida, 2002: Coastal lows along the subtropical west coast of South America: Mean structure and evolution. Mon. Wea. Rev., 130, 75-88, doi:10.1175/ 1520-0493(2002)130<0075:CLATSW > 2.0.CO;2.

Goddard, L., A. G. Barnston, and S. J. Mason, 2003: Evaluation of the IRI's "net assessment" seasonal climate forecasts: 1997-2001. Bull. Amer. Meteor. Soc., 84, 1761-1781, doi:10.1175/BAMS-84-12-1761. , W. E. Baethgen, H. Bhojwani, and A. W. Robertson, 2014: The International Research Institute for Climate \& Society: Why, what and how. Earth Perspect., 1, 10, doi:10.1186/2194-6434-1-10.

Greene, A. M., L. Goddard, and R. Cousin, 2011: Web tool deconstructs variability in twentieth-century climate. Eos, Trans. Amer. Geophys. Union, 92, 397, doi:10.1029/2011EO450001.

Grimm, A. M., and R. G. Tedeschi, 2009: ENSO and extreme rainfall events in South America. J. Climate, 22, 1589-1609, doi:10.1175/2008JCLI2429.1.

Jones, C., and L. M. V. Carvalho, 2002: Active and break phases in the South American monsoon system. J. Climate, 15, 905-914, doi:10.1175/1520-0442(2002)015<0905:AABPIT>2.0.CO;2.

Kalnay, E., and Coauthors, 1996: The NCEP/NCAR 40-Year Reanalysis Project. Bull. Amer. Meteor. Soc., 77, 437-471, doi:10.1175/1520-0477(1996)077<0437:TNYRP>2.0.CO;2.

Kiladis, G. N., and K. M. Weickmann, 1997: Horizontal structure and seasonality of large-scale circulations associated with submonthly tropical convection. Mon. Wea. Rev., 125, 19972013, doi:10.1175/1520-0493(1997)125<1997:HSASOL > 2.0.CO;2.

Kistler, R., and Coauthors, 1999: The NCEP-NCAR 50-Year Reanalysis: Monthly means CD-ROM and documentation. Bull. Amer. Meteor. Soc., 82, 247-267, doi:10.1175/ 1520-0477(2001)082<0247:TNNYRM > 2.3.CO;2.

Labraga, J. C., B. Scian, and O. Frumento, 2002: Anomalies in the atmospheric circulation associated with the rainfall excess or deficit in the Pampa Region in Argentina. J. Geophys. Res., 107, 4666, doi:10.1029/2002JD002113.

Liebmann, B., G. N. Kiladis, J. Marengo, T. Ambrizzi, and J. D. Glick, 1999: Submonthly convective variability over South America and the South Atlantic convergence zone. J. Climate, 12, 1877-1891, doi:10.1175/1520-0442(1999)012<1877: SCVOSA $>2.0 . \mathrm{CO} ; 2$

Marengo, J. A., W. R. Soares, C. Saulo, and M. Nicolini, 2004: Climatology of the low-level jet east of the Andes as derived from the NCEP-NCAR reanalyses: Characteristics and temporal variability. J. Climate, 17, 2261-2280, doi:10.1175/ 1520-0442(2004)017<2261:COTLJE > 2.0.CO;2.

Marshall, G. J., 2003: Trends in the southern annular mode from observations and reanalyses. J. Climate, 16, 4134-4143, doi:10.1175/1520-0442(2003)016<4134:TITSAM>2.0.CO;2.

Mason, S. J., and O. Baddour, 2008: Statistical modelling. Seasonal Climate: Forecasting and Managing Risk, A. Troccoli et al., Eds., Vol. 82, NATO Science Series: IV: Earth and Environmental Sciences, Springer, 163-201.

Mechoso, C. R., and Coauthors, 2001: Climatology and hydrology of La Plata Basin. Accessed 24 Sep 2014. [Available online at http://www.atmos.umd.edu/ berbery/lpb/ science_plan.html.] 
Meehl, G. A., and Coauthors, 2009: Decadal prediction: Can it be skillful? Bull. Amer. Meteor. Soc., 90, 1467-1485, doi:10.1175/ 2009BAMS2778.1.

Michelangeli, P.-A., R. Vautard, and B. Legras, 1995: Weather regimes: Recurrence and quasi stationarity. J. Atmos. Sci., 52, 1237-1256, doi:10.1175/1520-0469(1995)052<1237:WRRAQS>2.0.CO;2.

Minetti, J. L., W. M. Vargas, and A. G. Poblete, 1993: Comportamiento interestacional e interanual del borde oriental del Anticiclón del Pacífico Sur. Geofísica, 38, 79-89.

Mo, K. C., and J. Nogues-Paegle, 2001: The Pacific-South American modes and their downstream effects. Int. J. Climatol., 21 1211-1229, doi:10.1002/joc.685.

Moron, V., A. W. Robertson, and M. N. Ward, 2006: Seasonal predictability and spatial coherence of rainfall characteristics in the tropical setting of Senegal. Mon. Wea. Rev., 134, 32483262, doi:10.1175/MWR3252.1.

,--1, and P. Camberlin, 2007: Spatial coherence of tropical rainfall at the regional scale. J. Climate, 20, 5244-5263, doi:10.1175/2007JCLI1623.1.

Muñoz, Á. G., and Coauthors, 2010: An environmental watch system for the Andean countries: El Observatorio Andino. Bull. Amer. Meteor. Soc., 91, 1645-1652, doi:10.1175/2010BAMS2958.1.

—- and Coauthors, 2012: Risk management at the Latin American Observatory. Risk Management-Current Issues and Challenges, N. Banaitiene, Ed., InTech, 532-556.

Muza, M. N., L. M. V. Carvalho, C. Jones, and B. Liebmann, 2009: Intraseasonal and interannual variability of extreme dry and wet events over southeastern South America and the subtropical Atlantic during austral summer. J. Climate, 22, 1682 1699, doi:10.1175/2008JCLI2257.1.

Nicolini, M., and A. C. Saulo, 2000: ETA characterization of the 19971998 warm season Chaco jet cases. Proc. Sixth Int. Conf. on Southern Hemisphere Meteorology and Oceanography, Santiago, Chile, Amer. Meteor. Soc., 12C.1. [Available online at https:// ams.confex.com/ams/other/techprogram/paper_10722.htm.]

,-- J. C. Torres, and P. Salio, 2002: Strong South American low-level jet events characterization during warm season and implications for enhanced precipitation. Meteorológica, 27, 59-69.

Nnamchi, H. C., J. Li, and R. N. C. Anyadike, 2011: Does a dipole mode really exist in the South Atlantic Ocean? J. Geophys. Res., 116, D15104, doi:10.1029/2010JD015579.

Penalba, O. C., M. L. Bettolli, and P. A. Krieger, 2013: Surface circulation types and daily maximum and minimum temperatures in southern La Plata basin. J. Appl. Meteor. Climatol., 52, 2450-2459, doi:10.1175/JAMC-D-13-039.1.

Peters, J. M., and P. J. Roebber, 2014: Synoptic control of heavyrain-producing convective training episodes. Mon. Wea. Rev., 142, 2464-2482, doi:10.1175/MWR-D-13-00263.1.

Petersen, W. A., R. Cifelli, D. J. Boccippio, S. A. Rutledge, and C. Fairall, 2003: Convection and easterly wave structures observed in the eastern Pacific warm pool during EPIC-2001. J. Atmos. Sci., 60, 1754-1773, doi:10.1175/ 1520-0469(2003)060<1754:CAEWSO > 2.0.CO;2.

Racsko, P., L. Szeidl, and M. Semenov, 1991: A serial approach to local stochastic weather models. Ecol. Modell., 57, 27-41, doi:10.1016/0304-3800(91)90053-4.

Richardson, C. W., 1981: Stochastic simulation of daily precipitation, temperature, and solar radiation. Water Resour. Res., 17, 182-190, doi:10.1029/WR017i001p00182.

Robertson, A. W., and M. Ghil, 1999: Large-scale weather regimes and local climate over the western United States. J. Climate, 12, 1796-1813, doi:10.1175/1520-0442(1999)012<1796: LSWRAL $>2.0 . \mathrm{CO} ; 2$.
_ V. Moron, and Y. Swarinoto, 2009: Seasonal predictability of daily rainfall statistics over Indramayu district, Indonesia. Int. J. Climatol., 29, 1449-1462, doi:10.1002/joc.1816.

Roebber, P. J., K. L. Swanson, and J. K. Ghorai, 2008: Synoptic control of mesoscale precipitating systems in the Pacific Northwest. Mon. Wea. Rev., 136, 3465-3476, doi:10.1175/2008MWR2264.1.

Salio, P., M. Nicolini, and A. C. Saulo, 2002: Chaco low-level jet events characterization during the austral summer season. J. Geophys. Res., 107, 4816, doi:10.1029/2001JD001315.

$\longrightarrow,-$, and E. J. Zipser, 2007: Mesoscale convective systems over southeastern South America and their relationship with the South American low-level jet. Mon. Wea. Rev., 135, 12901309, doi:10.1175/MWR3305.1.

Seluchi, M. E., R. Garreaud, F. A. Norte, and A. C. Saulo, 2006: Influence of the subtropical Andes on baroclinic disturbances: A cold front case study. Mon. Wea. Rev., 134, 3317-3335, doi:10.1175/MWR3247.1.

Silva Dias, M. A. F., and Coauthors, 2002: Cloud and rain processes in a biosphere-atmosphere interaction context in the Amazon region. J. Geophys. Res., 107, 8072, doi:10.1029/2001JD000335.

Silvestri, G. E., and C. S. Vera, 2003: Antarctic Oscillation signal on precipitation anomalies over southeastern South America. Geophys. Res. Lett., 30, 2115, doi:10.1029/2003GL018277.

Sirovich, L., M. Y. Stoeckle, and Y. Zhang, 2009: A scalable method for analysis and display of DNA sequences. PLoS One, 4, e7051, doi:10.1371/journal.pone.0007051.

Smith, T. M., R. W. Reynolds, T. C. Peterson, and J. Lawrimore, 2008: Improvements to NOAA's historical merged landocean surface temperature analysis (1880-2006). J. Climate, 21, 2283-2296, doi:10.1175/2007JCLI2100.1.

Stockdale, T. N., and Coauthors, 2011: ECMWF Seasonal Forecast System 3 and its prediction of sea surface temperature. Climate Dyn., 37, 455-471, doi:10.1007/s00382-010-0947-3.

Trzaska, S., A. W. Robertson, J. D. Farrara, and C. R. Mechoso, 2007: South Atlantic variability arising from air-sea coupling: Local mechanisms and tropical-subtropical interactions. J. Climate, 20, 3345-3365, doi:10.1175/JCLI4114.1.

Van der Wiel, K., A. J. Matthews, D. P. Stevens, and M. M. Joshi, 2015: A dynamical framework for the origin of the diagonal South Pacific and South Atlantic convergence zones. Quart. J. Roy. Meteor. Soc., doi:10.1002/qj.2508, in press.

Vautard, R., 1990: Multiple weather regimes over the North Atlantic: Analysis of precursors and successors. Mon. Wea. Rev., 118, 2056-2081, doi:10.1175/1520-0493(1990)118<2056: MWROTN $>2.0 . \mathrm{CO} ; 2$.

Velasco, I., and J. M. Fritsch, 1987: Mesoscale convective complexes in the Americas. J. Geophys. Res., 92, 9591-9613, doi:10.1029/ JD092iD08p09591.

Viale, M., and M. N. Nuñez, 2011: Climatology of winter orographic precipitation over the subtropical central Andes and associated synoptic and regional characteristics. J. Hydrometeor., 12, 481-507, doi:10.1175/2010JHM1284.1.

Wheeler, M. C., and H. H. Hendon, 2004: An all-season real-time multivariate MJO index: Development of an index for monitoring and prediction. Mon. Wea. Rev., 132, 1917-1932, doi:10.1175/1520-0493(2004)132<1917:AARMMI>2.0.CO;2.

WMO, 2013: Sub-seasonal to seasonal prediction: Research implementation plan. WMO, $71 \mathrm{pp}$. [Available online at http://www. wmo.int/pages/prog/arep/wwrp/new/S2S_project_main_page.html.]

Zhou, Z., and J. A. Carton, 1998: Latent heat flux and interannual variability of the coupled atmosphere-ocean system. J. Atmos. Sci., 55, 494-501, doi:10.1175/1520-0469(1998)055<0494: LHFAIV $>2.0 . \mathrm{CO} ; 2$ 